Engineering Journal

Elsevier Editorial System(tm) for Chemical

Manuscript Draft

Manuscript Number: CEJ-D-19-02276R1

Title: Sustainability of Treatment Technologies for Industrial Biowastes Effluents

Article Type: VSI: Conversion of Biowaste

Keywords: Sustainability, Fuzzy-Delphi methodology, Biowastes, Physicochemical methods, Membrane technologies, Biological methods

Corresponding Author: Dr. Tejraj M Aminabhavi, PhD

Corresponding Author's Institution: College of Pharmacy

First Author: Tejraj M Aminabhavi, PhD

Order of Authors: Tejraj M Aminabhavi, PhD; Mohammadreza Kamali, Ph. D.; Maria Elisabete Costa, Ph. D.; Isabel Capela, Ph. D.

Abstract: Despite the huge efforts to develop efficient technologies for the treatment of recalcitrant biowastes and other emerging pollutants, selecting the most sustainable method among the possible alternatives is still a formidable task. This is mainly because of the integration of technical, economic, environmental, and social criteria in decisionmaking process. Traditionally, various multi-criteria decision-making approaches have been adopted to integrate innumerable criteria for environmental applications. In this study, we have examined the fuzzyDelphi approach to evaluate seventeen parameters for integrating technical, economic, environmental and social criteria in order to rank the nine treatment technologies divided in two categories (physicochemical and biological processes). The results of this study indicated that although efficiency of treatment methods is the most important criterion, but contribution of other sustainability criteria should also be considered because they are of high importance for the selection of sustainable wastewater treatment methods. As per our proposed framework on membrane technologies (among the many other physico-chemical methods) and anaerobic sludge blanket technology (among the biological treatment methods) are the most promising approaches for the treatment of highly polluted emerging industrial pollutants. The findings of this study are fully supported by the consensus achieved by a group of fifty experts from nineteen different countries. Opportunities for the improvement of the methods as per data generated are discussed.

Response to Reviewers: Ms. Ref. No.: CEJ-D-19-02276

Title: Sustainability of Treatment Technologies for Industrial Biowastes Effluents

Chemical Engineering Journal

Reviewers' comments:

Reviewer \#2:

General comment: 
This is a useful work to help improve sustainability of biowaste and wastewater treatment. This can be accepted for publication in CEJ after minor modification.

Response: We would like to appreciate the positive view of the reviewer about our manuscript.

Comment (1): While the authors state the originality and novelty of this work in introduction section, please emphasize the difference between the current work and previously published works.

Response: Modifications have been applied (Line 86).

"The difference between the current work and previously published works" is now emphasized in the introduction, lines 86-89.

Comment (2): In my humble opinion, integration of section 1 and section 2 would be better.

Response: Modifications have been applied. Sections 1 and 2 are now merged.

Comment (3): In Tables 3, 4, 5, and 6, why don't you use dot(.) instead of comma $($,$) to express decimals?$

Response: Modifications have been applied. The commas (,) in Tables 3, 4, and 6 have been replaced by dots (.).

Reviewer \#3:

General comment:

This article used the fuzzy-Delphi method to comprehensively evaluate the seventeen parameters for integrating technical, economic, environmental and social criteria in the industrial biowastes effluent treatment. And nine popular technologies was evaluated in two typical categories. The results provided an alternative during the decision-making process when choosing treatment process. In general, the structure of this manuscript was well-organized. Below are some comments that may help the authors to improve the quality.

Recommendation: minor revision.

We would like to appreciate the positive opinion of the reviewer about our manuscript.

Comment: Introduction. Page 2, Line 6, the abbreviation 'MCDAs' should be explained when first mentioned. Is that one kind of MCDM process?

Response: Modifications have been applied. "MCDAs" has been changed to MCDM which has been previously defined in the text of the manuscript.

Page 2, Line 50 .

Comment: Methodology. Page 5, Line 37-38, the specific mean of 'L, M, U' in aggregated fuzzy numbers ( $\mathrm{mL}, \mathrm{mM}$, $\mathrm{mU}$ ) should be introduced.

Response: Modifications have been applied. The specific meaning of $L$, M, and $U$ is now introduced in the text, Page 4 line 123-124.

Comment: Discussion. Page 7, Table 4, it could be obviously seen that the Sub-Criterion of CO2 emission received the least concern according to the calculated value of De-fuzzy. Should it be distinguished from the normal environmental criteria? It also seems to be a social criterion in many situations.

Response: Modifications have been applied. Page 7, Lines 178-181.

A text has been added to the manuscript clarifying why this criterion should be considered despite its relative low value (because its de-fuzzy value lies above 0.5 which is fair).

It should be mentioned that $\mathrm{CO} 2$ emission and all criteria which may bring some social consequences may affect the overall perception of the communities. In this regard this study has proposed another criterion in Social Criteria named "public acceptance" to emphasize the importance of the public opinion on a certain technology (see for instance table 4 and figure 1).

Comment: Page 9, Line 4-20, except for the Sub-Criterion of CO2 emission, the value of other environmental sub-Criteria was close to 
economic. Some discussion could be added here to make the analysis more comprehensive.

Response: Modifications have been applied. Line 7, Lines 185-92.

A small text has been added to this section attempting to discuss the related importance of environmental and social criteria compared to technical and social criteria in the experts' points of view.

Comment: Page 13, Line 48, the full name of AOXs should be specified. Response: Modifications have been applied. Line 10, Lines 238. Comment: Page 14, Line 50, Fig. 3 was not found through the whole manuscript.

Response: Modifications have been applied. Page 12, Line 275. The reference to Fig. 3 was a mistake. The reference was updated. Comment: Page 16-18, the authors reviewed the characteristics of some physic-chemical water treatment methods. However, the link of these methods and the value of De-fuzzy was kindly ignored. It would be better to discuss with the data from former section, as the discussion in 4.3.2 Biological treatments did.

Response: Modifications have been applied. Page 11- Line 255, Page 12Line 256, Page 13- Lines 287-289, Page 14- Line 310, Page 14- Lines 332333.

Some links have been provided through this section aiming to connect Table 5 (De-fuzzy values) and the suggestions we provided based on literature review.

Comment: Page 18, Eq.5, the M+ is supposed to be Mn+, so that it is corresponding with 'ne-'.

Response: We thank the reviewer for this comment. In fact, equations 5 and 6 intend to describe the dissolution of anode zero valent metal (MO) as metallic cation $(\mathrm{Mn}+)$ of $(\mathrm{n}+)$ valence accompanied by electrons (ne-) release and the generation of gaseous hydrogen (H2 (g)) and hydroxide ions (OH-) that follows at the cathode. Taking into account the comment of the reviewer, we modified the equations aiming to minimize any possibility of misinterpretation.

Comment: The discussion of biotreatment was not as abundant as the physic-chemical methods. The fig.3 lost seems important.

Response: Many thanks to the reviewer for this comment. We totally agree with the comment of the reviewer. However due to the fact that there is a space limitation imposed to original manuscripts, a decision was made in terms of the methods to be more thoroughly discussed. Considering that at the moment physico-chemical methods (as the novel treatment methods for industrial wastewater treatment) are in the stage of being transferred from lab to real-scale applications, we decided to provide more discussions on possible improvements to accelerate their commercialization. 
Tejraj M. Aminabhavi

Editor, Chemical Engineering Journal [Elsevier, USA]

PhD., (The University of Texas at Austin, Texas USA)

Professor and Research Director, Soniya College of Pharmacy, Dharwad 580 002, India

Mob: +91-9449821279; aminabhavit@gmail.com

Website: https://sites.google.com/site/proftejrajaminabhavi/home

Google Scholar: https://scholar.google.co.in/citations?user=66tWHWOAAAAJ\&hl=en

Research Director: http://www.soniyapharmacy.org/m2_.php

Chair Person Advisory Committee: http://sdpc.co.in/

March, 26 ${ }^{\text {th }}, 2019$

Professor You Fai Tsang, Special Issue Editor

Journal of Chemical Engineering (under Thematic Special Issue "Thermochemical Conversion of Biowaste on Energy and Resource Recovery and Pollution Abatement")

Dear Prof. Tsang

I am herewith submitting the completely revised copy of the manuscript entitled

Sustainability of Treatment Technologies for Industrial Biowastes Effluents

Mohammadreza Kamali ${ }^{1,2}$, Maria Elisabete Costa ${ }^{2}$, Tejraj M. Aminabhavi ${ }^{*}{ }^{3}$, Isabel Capela ${ }^{* 1}$

${ }^{1}$ Department of Environment and Planning, Center for Environmental and Marine Studies, CESAM, University of Aveiro, 3810-193 Aveiro, Portugal

2 Department of Materials and Ceramics Engineering, Aveiro Institute of Materials, CICECO, University of Aveiro, 3810-193 Aveiro, Portugal

3 Pharmaceutical Engineering, Soniya College of Pharmacy, Dharwad, India 580-002

For further consideration to the publication in CEJ

Conflict of interest:

All the authors have equally contributed towards the preparation of this review and were participated equally during revision of the work. There is no conflict of interest. All of us agree and are responsible to the statements presented in this revised work.

Please address all correspondence concerning this manuscript to Professor Tejraj Aminabhavi at aminabhavit@gmail.com

Thank you very much for your consideration of this review in CEJ special issue.

Sincerely,

Dr. Tejraj Aminabhavi

Professor and Research Director

Soniya College of Pharmacy, Dharwad 580 002, India

Email: aminabhavit@gmail.com; Mob: +91-9449821279

*Corresponding authors: Isabel Capela (icapela@ua.pt) and Tejraj Aminabhavi (aminabhavit@gmail.com). 
Ms. Ref. No.: CEJ-D-19-02276

Title: Sustainability of Treatment Technologies for Industrial Biowastes Effluents Chemical Engineering Journal

Reviewers' comments:

Reviewer \# 2:

General comment:

This is a useful work to help improve sustainability of biowaste and wastewater treatment. This can be accepted for publication in CEJ after minor modification.

Response: We would like to appreciate the positive view of the reviewer about our manuscript.

Comment (1): While the authors state the originality and novelty of this work in introduction section, please emphasize the difference between the current work and previously published works.

Response: Modifications have been applied (Line 86).

"The difference between the current work and previously published works" is now emphasized in the introduction, lines 86-89.

Comment (2): In my humble opinion, integration of section 1 and section 2 would be better.

Response: Modifications have been applied. Sections 1 and 2 are now merged.

Comment (3): In Tables 3, 4, 5, and 6, why don't you use dot(.) instead of comma(,) to express decimals?

Response: Modifications have been applied. The commas (,) in Tables 3, 4, and 6 have been replaced by dots (.).

\section{Reviewer \#3:}

General comment:

This article used the fuzzy-Delphi method to comprehensively evaluate the seventeen parameters for integrating technical, economic, environmental and social criteria in the industrial biowastes effluent treatment. And nine popular technologies was evaluated in two typical categories. The results provided an alternative during the decision-making process when choosing treatment process. In general, the structure of this manuscript was well-organized. Below are some comments that may help the authors to improve the quality.

Recommendation: minor revision. 
We would like to appreciate the positive opinion of the reviewer about our manuscript.

Comment: Introduction. Page 2, Line 6, the abbreviation 'MCDAs' should be explained when first mentioned. Is that one kind of MCDM process?

Response: Modifications have been applied. "MCDAs" has been changed to MCDM which has been previously defined in the text of the manuscript. Page 2, Line 50.

Comment: Methodology. Page 5, Line 37-38, the specific mean of 'L, $M, U$ ' in aggregated fuzzy numbers ( $m L, m M, m U)$ should be introduced.

Response: Modifications have been applied. The specific meaning of L, M, and U is now introduced in the text, Page 4 line 123-124.

Comment: Discussion. Page 7, Table 4, it could be obviously seen that the SubCriterion of $\mathrm{CO}_{2}$ emission received the least concern according to the calculated value of De-fuzzy. Should it be distinguished from the normal environmental criteria? It also seems to be a social criterion in many situations.

Response: Modifications have been applied. Page 7, Lines 178-181.

A text has been added to the manuscript clarifying why this criterion should be considered despite its relative low value (because its de-fuzzy value lies above 0.5 which is fair).

It should be mentioned that $\mathrm{CO}_{2}$ emission and all criteria which may bring some social consequences may affect the overall perception of the communities. In this regard this study has proposed another criterion in Social Criteria named "public acceptance" to emphasize the importance of the public opinion on a certain technology (see for instance table 4 and figure 1 ).

Comment: Page 9, Line 4-20, except for the Sub-Criterion of $\mathrm{CO}_{2}$ emission, the value of other environmental Sub-Criteria was close to economic. Some discussion could be added here to make the analysis more comprehensive.

Response: Modifications have been applied. Line 7, Lines 185-92.

A small text has been added to this section attempting to discuss the related importance of environmental and social criteria compared to technical and social criteria in the experts' points of view.

Comment: Page 13, Line 48, the full name of AOXs should be specified.

Response: Modifications have been applied. Line 10, Lines 238.

Comment: Page 14, Line 50, Fig. 3 was not found through the whole manuscript.

Response: Modifications have been applied. Page 12, Line 275. 
The reference to Fig. 3 was a mistake. The reference was updated.

Comment: Page 16-18, the authors reviewed the characteristics of some physicchemical water treatment methods. However, the link of these methods and the value of De-fuzzy was kindly ignored. It would be better to discuss with the data from former section, as the discussion in 4.3.2 Biological treatments did.

Response: Modifications have been applied. Page 11- Line 255, Page 12- Line 256, Page 13- Lines 287-289, Page 14- Line 310, Page 14- Lines 332-333.

Some links have been provided through this section aiming to connect Table 5 (Defuzzy values) and the suggestions we provided based on literature review.

Comment: Page 18, Eq.5, the $M+$ is supposed to be $M n+$, so that it is corresponding with 'ne-'.

Response: We thank the reviewer for this comment. In fact, equations 5 and 6 intend to describe the dissolution of anode zero valent metal $\left(\mathrm{M}^{\circ}\right)$ as metallic cation $\left(\mathrm{M}^{\mathrm{n}+}\right)$ of $(\mathrm{n}+)$ valence accompanied by electrons (ne-) release and the generation of gaseous hydrogen $\left(\mathrm{H}_{2}(\mathrm{~g})\right)$ and hydroxide ions $\left(\mathrm{OH}^{-}\right)$that follows at the cathode. Taking into account the comment of the reviewer, we modified the equations aiming to minimize any possibility of misinterpretation.

Comment: The discussion of biotreatment was not as abundant as the physicchemical methods. The fig.3 lost seems important.

Response: Many thanks to the reviewer for this comment. We totally agree with the comment of the reviewer. However due to the fact that there is a space limitation imposed to original manuscripts, a decision was made in terms of the methods to be more thoroughly discussed. Considering that at the moment physico-chemical methods (as the novel treatment methods for industrial wastewater treatment) are in the stage of being transferred from lab to real-scale applications, we decided to provide more discussions on possible improvements to accelerate their commercialization. 


\section{Graphical Abstract
\[ \begin{array}{c}\text { Delphi-Fuzzy Approch for } \\ \text { Industrial Biowastes Efiluents Treatment }\end{array} \] \\ Graphical Abstract
\[ \begin{array}{c}\text { Delphi-Fuzzy Approch for } \\ \text { Industrial Biowastes Efiluents Treatiment }\end{array} \] Method Selection}

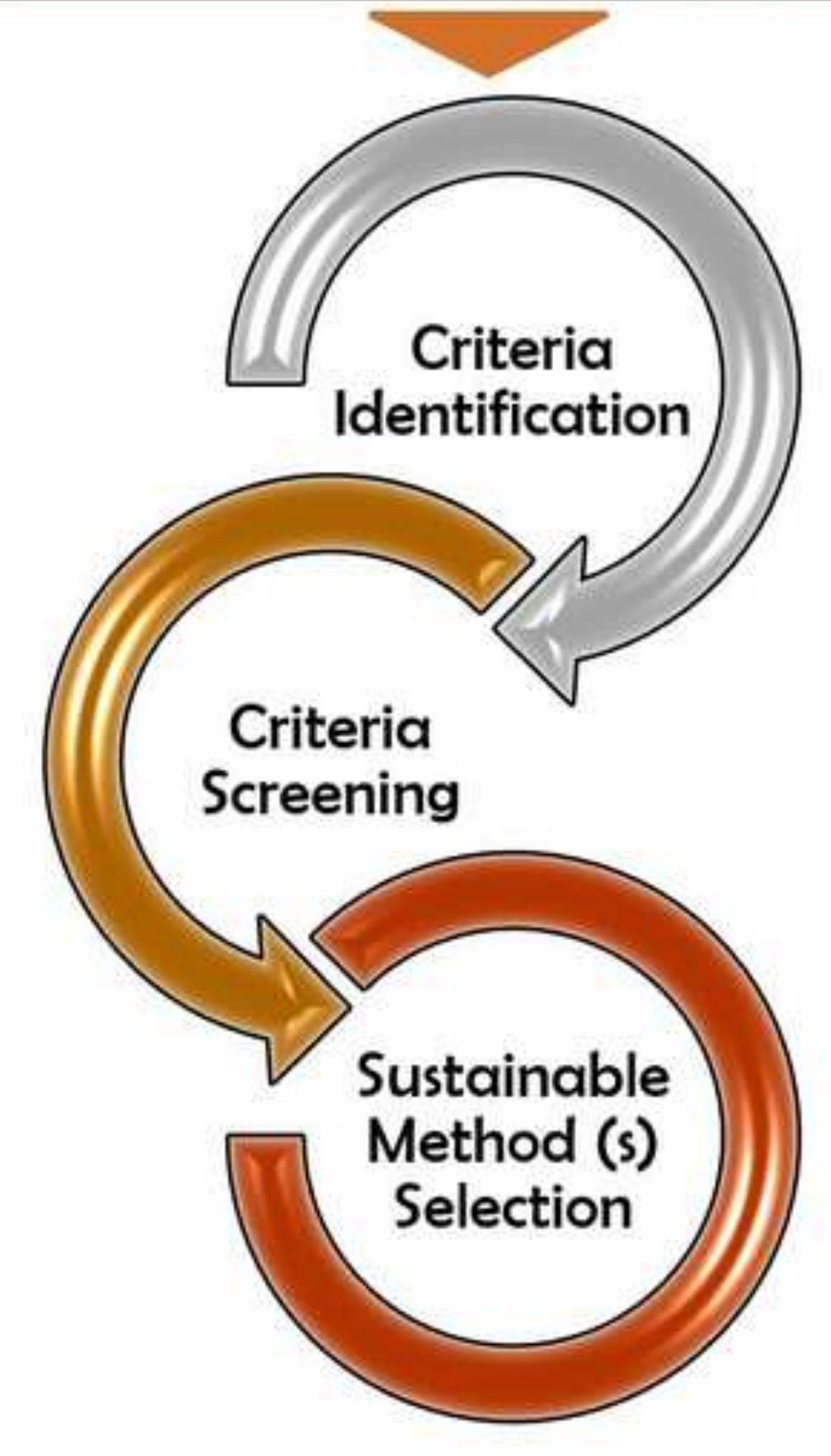

\section{Screening}

Sustainable Method (s) Selection

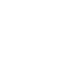
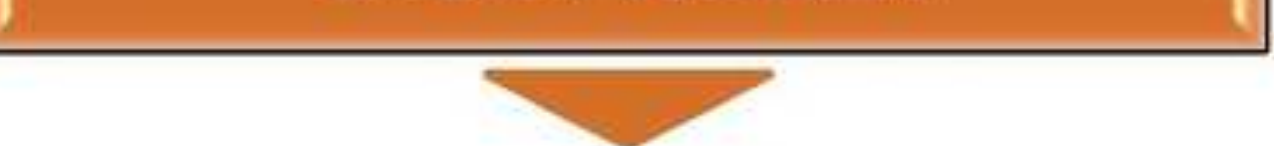


\section{Highlights:}

- The most important criteria for the treatments of industrial wastewater are studied.

- Applications of various physico-chemical and biological methods are assessed for the treatment of industrial effluents.

- Opportunities for industrial wastewater treatment methods are discussed. 


\title{
1 Sustainability of Treatment Technologies for Industrial \\ Biowastes Effluents
}

\author{
Mohammadreza Kamali ${ }^{1,2}$, Maria Elisabete Costa ${ }^{2}$, Tejraj M. Aminabhavi ${ }^{*}{ }^{3}$, Isabel Capela ${ }^{* 1}$
}

\author{
${ }^{1}$ Department of Environment and Planning, Center for Environmental and Marine Studies, \\ CESAM, University of Aveiro, 3810-193 Aveiro, Portugal \\ ${ }^{2}$ Department of Materials and Ceramics Engineering, Aveiro Institute of Materials, CICECO, \\ University of Aveiro, 3810-193 Aveiro, Portugal \\ 3 Pharmaceutical Engineering, Soniya College of Pharmacy, Dharwad, India 580-002
}

\section{Abstract}

Despite the huge efforts to develop efficient technologies for the treatment of recalcitrant biowastes and other emerging pollutants, selecting the most sustainable method among the possible alternatives is still a formidable task. This is mainly because of the integration of technical, economic, environmental, and social criteria in decision-making process. Traditionally, various multi-criteria decision-making approaches have been adopted to integrate innumerable criteria for environmental applications. In this study, we have examined the fuzzy-Delphi approach to evaluate seventeen parameters for integrating technical, economic, environmental and social criteria in order to rank the nine treatment technologies divided in two categories (physico-chemical and biological processes). The results of this study indicated that although efficiency of treatment methods is the most important criterion, but contribution of other sustainability criteria should also be considered because they are of high importance for the selection of sustainable wastewater treatment methods. As per our proposed framework on membrane technologies (among the many other physicochemical methods) and anaerobic sludge blanket technology (among the biological treatment methods) are the most promising approaches for the treatment of highly polluted emerging industrial pollutants. The findings of this study are fully supported by the consensus achieved by a group of fifty experts from nineteen different countries. Opportunities for the improvement of the methods as per data generated are discussed.

\footnotetext{
*Corresponding authors: Isabel Capela (icapela@ua.pt) and Tejraj Aminabhavi (aminabhavit@gmail.com).
} 


\section{Keywords}

30

Sustainability, Fuzzy-Delphi methodology, Biowastes, Physico-chemical methods, Membrane technologies, Biological methods

\section{Introduction}

Quality of the final discharged emerging effluents from innumerable industrial activities has been the subject of much debate over the past decades for improving the performance of the methods used either by physico-chemical, biological or a combination of these processes. On the other hand, industries around the world, particularly textile or pulp and paper industries are struggling for their economic profitability [1]. In this situation, stringent environmental regulations have forced the industries, especially those releasing the recalcitrant biowastes compounds, to adopt more efficient treatment methods. Therefore, it is vital to consider both the importance of technical and economic factors while selecting the most appropriate treatment technologies [2]. In addition, long-term sustainability considerations enforce the industries to include environmental and health issues [3] along with the social criteria in decision-making process for selecting the best treatment strategies [4]. Integration of all these aspects while selecting the most appropriate techniques for the treatment of recalcitrant biowastes in industrial effluents is a complex task requiring the need for a multi-criteria analysis framework to identify the most suitable technology.

Due to the inherent advantages of multi-criteria decision making (MCDM) approaches $[5,6]$, such as their strong structure and logic [7], they have been effectively applied to support the decision makers to choose the most appropriate alternative to solve innumerable environmental problems [8]. Delphi, as a MCDM process, is basically conducted through a group of decision-making among the experts with different experiences and knowledge on the same application domain. Two main applications of this process are screening the criteria and forecasting (or evaluating) the performance of a method or technology [9]. Fuzzy-Delphi method (FDM) has thus been developed by the application of traditional Delphi methodology in a fuzzy environment. This technique has been previously employed in sustainable decisions in various fields [10-12]. In this study, we have employed FDM to assess the current opinion of experts in the field of various conventional and emerging technologies for the treatment of recalcitrant biowastes arising from pulp, paper and textile industries. 
Selecting the most appropriate technologies to deal with the recalcitrant biowastes and other emerging pollutants in the context of industrial effluents to satisfy the stringent environmental standards while considering various technical, environmental, economic and social aspects is a complex task [13]. Multi-criteria decision analysis, as a set of methods allows to identify the most important criteria to rank the available alternatives [14,15]. Even though these methods have been extensively used to rank the relevant criteria to select the most suitable alternatives in various scientific fields, yet only handful of reports are available on the application of MCDMs for selecting suitable wastewater treatment technologies. Arroyo and Molinos-Senante [2] used choosing-by-advantages (CBA) approach to select the most suitable municipal wastewater treatment technology among the widely used methods (constructed wetlands, pond systems, extended aeration, membrane bioreactor [16], rotating biological contactor, trickling filter and sequencing batch reactor) by considering several criteria including treatment efficiency, energy consumption, land area required, sewage sludge production, potential for water reuse, potential to recover by-products, reliability, odor impact, noise impact, visual impact, public acceptance, and complexity of operation. According to the opinions of nineteen participants in this research, odor impact was identified as the most important sustainability criterion and the extended aeration together with the sequencing batch reactor were ranked as the most promising treatment technologies.

A "technique for order of preference by similarity to ideal solution" (TOPSIS) approach was also used in some studies. For instance, Dursun [17] using this technique indicated that sustainability is the most important parameter among the studied factors (i.e., cost, global warming, eutrophication, land requirement, manpower requirement, reliability, sustainability and flexibility). However, the method of sequencing batch reactors (SBRs) is the best approach among of all the investigated technologies (i.e., activated sludge, up-flow anaerobic sludge blanket followed by a facultative aerated lagoon, sequential batch reactor, constructed wetlands). Analytical hierarchy process (AHP) has also been used in recent years in its conventional and advanced forms (e.g., AHP fuzzy approach) in order to select the best wastewater treatment technologies. For instance, Ouyang et. al [18] employed the integrated fuzzy analytical hierarchy process for selecting natural wastewater treatment alternatives. However, the fuzzy-Delphi method for ranking the influencing criteria and to prioritize the most suitable technologies to deal with industrial effluents loaded with recalcitrant biowastes has not been studied hitherto considering both conventional and novel treatment technologies. 


\subsection{Problem description and criteria identification}

91

92

93

94

Some efforts have been made to identify the most appropriate sewage treatment technologies using the multi criteria decision making processes [2]. However, there is a need to understand the current opinion of scientific community on the most important parameters to identify the most suitable technologies to deal with the industrial effluents as per sustainable development goals. In this investigation, seventeen criteria including technical (i.e., treatment efficiency, ease of implementation, combination possibility, process stability, and health and safety risks), environmental (i.e., biowaste waste generation, release of chemical substances, $\mathrm{CO}_{2}$ emission, water reuse potential, and recovery of by-products), economic (i.e., initial investments, maintenance costs, and operating costs), and social (odor impact, noise impact, visual impact, and public acceptance) were considered in order to rank the studied methods for the treatment of industrial effluents. Table 1 presents a list of the studied subcriteria and their descriptions have been provided in the supplementary information.

Table 1. The descriptions of the studied criteria

\begin{tabular}{ll}
\hline Criteria & Description \\
\hline Treatment Efficiency & Effectiveness of the method for the treatment of recalcitrant biowastes from \\
& industrial effluents, considering all treatment parameters such as operating \\
& conditions, additives, etc.. \\
Ease of Implementation & The level of complexity of the method in terms of required equipment, \\
& expertise needed, etc. \\
Combination Possibility & The combination potential of the method with other treatment methods. \\
Process Stability & Overall reliability of the treatment method against failures and possibility of \\
Health and Safety risks & The-establishment after probable failures. \\
Solid Wastes Generation & method. \\
Welease of Chemical Substances & Solid wastes (e.g., biowaste generation when the treatment method is \\
& applied.
\end{tabular}




\begin{tabular}{|c|c|}
\hline Potential to Recover By-Products & Possibility of the by-products recovery i.e., energy and materials. \\
\hline Initial Investments & $\begin{array}{l}\text { Required initial investments (including land area, equipment, } \\
\text { infrastructures, certificates, etc.). }\end{array}$ \\
\hline Maintenance Cost & Overall costs required for the maintenance of the facilities. \\
\hline Operating Costs & Overall costs required for energy, materials, labor, etc. \\
\hline Odor Impact & Odor generated from the treatment process. \\
\hline Noise Impact & Noise produced from the process. \\
\hline Visual Impact & Impact of the treatment infrastructures on the local visual properties. \\
\hline Public Acceptance & $\begin{array}{l}\text { Overall public community's perception about the usefulness of the method } \\
\text { for their routine life. }\end{array}$ \\
\hline
\end{tabular}

In this study, expert questionnaires were assisted to collect the current opinion of experts on the performance of the studied treatment methods. A careful protocol was followed to invite experts with excellent academic and/or industrial experience in the concerned area. Linguistic variables and triangular fuzzy numbers (Tables 2 and 3) were utilized in order to determine the importance of evaluation criteria and to rate the studied alternative methods. The questionnaire used to collect the opinion of the experts was provided in the supplementary information.

A fuzzy number is principally defined as a fuzzy set to elaborate a fuzzy interval in the real number, R. Fuzzy numbers are used to explain uncertain information in decision making process [19]. A triangular fuzzy number (as a type of fuzzy numbers) is defined as: $A=\left(\mathrm{a}_{1}, \mathrm{a}_{2}, \mathrm{a}_{3}\right)$. Eq.1 is used to represent the triangular membership functions as [20]:

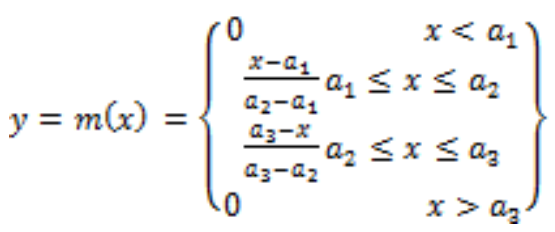

A vertex method was then used to estimate the consensus among the expert group (Eq. 2) 116 by computing the distance, $d(\widetilde{m}, \tilde{n})$, between the aggregated fuzzy numbers $\left(\mathrm{m}_{\mathrm{L}}, \mathrm{m}_{\mathrm{M}}, \mathrm{m}_{\mathrm{U}}\right)$ 117 computed from Eq. 3 and the triangular fuzzy numbers expressed by each expert in the form of linguistic terms.

$$
d(\widetilde{m}, \tilde{n})=\sqrt{\frac{1}{2}\left(m_{L}-n_{L}^{i}\right)^{2}+\left(m_{M}-n_{M}^{i}\right)^{2}+\left(m_{U}-n_{U}^{i}\right)^{2}} \quad \text { Eq.2 }
$$


121 The stability of results requires achieving of $75 \%$ of group consensus among the experts [22]. The

122 geometric mean (Eq. 3) [23] was utilized to calculate the fuzzy weights of the criteria and relative

123 efficiency of the industrial effluents treatment methods, in which L, M and U represent the fuzzy

124 number components.

$$
L_{j}=\operatorname{Min}_{i}\left\{L_{i j}\right\}, \quad M_{j}=\frac{1}{n} \sum_{i=1}^{n} M_{i j} . \quad U_{j}=\operatorname{Max}_{i}\left\{U_{i j}\right\}
$$

126 The above equation was used to calculate the relative importance of element number, $j$ allocated by 127 expert number, $i$. In order to perform defuzzification of the final triangular fuzzy numbers, Eq. 4 was utilized.

$$
d f=\frac{1}{4}(L+2 M+U)
$$

Table 2. Linguistic variables and the relevant fuzzy scales for the relative importance of the criteria

\begin{tabular}{lll}
\hline Linguistic variable & $\begin{array}{l}\text { Fuzzy Scale } \\
(\mathrm{L}, \mathrm{M}, \mathrm{U})\end{array}$ & $d f=\frac{1}{4}(L+2 M+U)$ \\
& & \\
\hline Extremely high & $(0.9,1.0,1.0)$ & 0.975 \\
Very high & $(0.7,0.9,1.0)$ & 0.875 \\
High & $(0.5,0.7,0.9)$ & 0.7 \\
Fair & $(0.3,0.5,0.7)$ & 0.5 \\
Low & $(0.1,0.3,0.5)$ & 0.3 \\
Very Low & $(0.0,0.1,0.3)$ & 0.125 \\
Extremely low & $(0.0,0.0,0.1)$ & 0.025 \\
\hline
\end{tabular}

Table 3. Linguistic variables and the relevant fuzzy scales to evaluate the efficiency of the methods

\begin{tabular}{lll}
\hline Linguistic variable & $\begin{array}{l}\text { Fuzzy Scale } \\
(\mathrm{L}, \mathrm{M}, \mathrm{U})\end{array}$ & $d f=\frac{1}{4}(L+2 M+U)$ \\
\hline Very good & $(0.75,1,1)$ & 0.937 \\
Good & $(0.5,0.75,1)$ & 0.75 \\
Fair & $(0.25,0.5,0.75)$ & 0.5 \\
Bad & $(0,0.25,0.5)$ & 0.25 \\
Very bad & $(0,0,0.25)$ & 0.0625 \\
\hline
\end{tabular}


where $r_{i j}$ is the rating of alternative, $i$ with respect to criteria, $j$ and $w_{j}$ is the $j_{\text {th }}$ criterion weight.

\section{Results and discussion}

Due to inherent complexity in selecting the most appropriate industrial effluents treatment method, it is not feasible to rely only on a single aspect such as the technical characteristics. An international panel consisting of fifty high-quality experts from nineteen countries (all over the world with academic and/or industrial experience) contributed in this study to determine the importance of each criterion and to rate the treatment methods according to their previous experiences on the application of different methods for industrial effluent treatment.

\subsection{Prioritization of the criteria}

Figure 1 and Table 4 present fuzzy weights of the studied criteria and sub-criteria after achieving the consensus among experts in the second round of questioning. As per data obtained technical considerations received the highest importance among the studied criteria, with a high relevance allocated to "treatment efficiency" and "health and safety risks". These results could reflect the fact that a technology to be chosen for mitigation of biowastes must be efficient and safe. Despite the fact that innumerable publications have been published on the performance of various industrial effluents treatments [21-24], the health and safety issues attributed to workers using those treatment technologies have not been well investigated. Exposure to biological agents (including bacteria, viruses, fungi (yeasts and mould) and parasites) is considered as one of the most important factors, which affect the safety and health of the workers. The entrance of the spores in human body via many ways such as respiratory tract, damaged skin, eye, etc. may cause severe health problems. In addition, environmental conditions such as humidity and temperature or their combination may provide a favorable environment for the growth of biological agents. Hence, the nature of treatment method applied, and the associated facilities could pose some risks. 
Table 4. Linguistic variables and the relevant fuzzy scale for the relative importance of the criteria

\begin{tabular}{|c|c|c|c|c|c|}
\hline \multirow[t]{2}{*}{ Criteria } & \multirow[t]{2}{*}{ Sub-Criteria } & \multicolumn{3}{|c|}{ Fuzzy values } & \multirow{2}{*}{$\begin{array}{l}\text { De- } \\
\text { fuzzy }\end{array}$} \\
\hline & & $\mathbf{L}$ & $\mathbf{M}$ & $\mathbf{U}$ & \\
\hline \multirow[t]{5}{*}{ Technical } & Treatment Efficiency (TE) & 0.50 & 0.90 & 1.00 & 0.83 \\
\hline & Ease of Implementation (EI) & 0.30 & 0.79 & 1.00 & 0.72 \\
\hline & Combination Possibility (CP) & 0.25 & 0.72 & 1.00 & 0.67 \\
\hline & Process Stability (PS) & 0.30 & 0.83 & 1.00 & 0.74 \\
\hline & Health and Safety Risks (HSR) & 0.50 & 0.90 & 1.00 & 0.83 \\
\hline \multirow[t]{5}{*}{ Environmental } & Solid Wastes (biowaste) Generation (SWG) & 0.10 & 0.79 & 1.00 & 0.67 \\
\hline & Release of Chemical Substances (RCS) & 0.00 & 0.90 & 1.00 & 0.70 \\
\hline & $\mathrm{CO}_{2}$ Emission (CE) & 0.00 & 0.74 & 1.00 & 0.62 \\
\hline & Water Reuse Potential (WRP) & 0.10 & 0.79 & 1.00 & 0.67 \\
\hline & Potential to Recover By-Products (PRB) & 0.25 & 0.75 & 1.00 & 0.69 \\
\hline \multirow[t]{3}{*}{ Economic } & Initial Investments (II) & 0.10 & 0.77 & 1.00 & 0.66 \\
\hline & Maintenance Cost (MC) & 0.10 & 0.80 & 1.00 & 0.67 \\
\hline & Operating Costs (OC) & 0.30 & 0.84 & 1.00 & 0.75 \\
\hline \multirow[t]{4}{*}{ Social } & Odor Impact (OI) & 0.10 & 0.74 & 1.00 & 0.64 \\
\hline & Noise Impact (NI) & 0.10 & 0.70 & 1.00 & 0.63 \\
\hline & Visual Impact (VI) & 0.00 & 0.64 & 1.00 & 0.57 \\
\hline & Public Acceptance (PA) & 0.00 & 0.75 & 1.00 & 0.63 \\
\hline
\end{tabular}

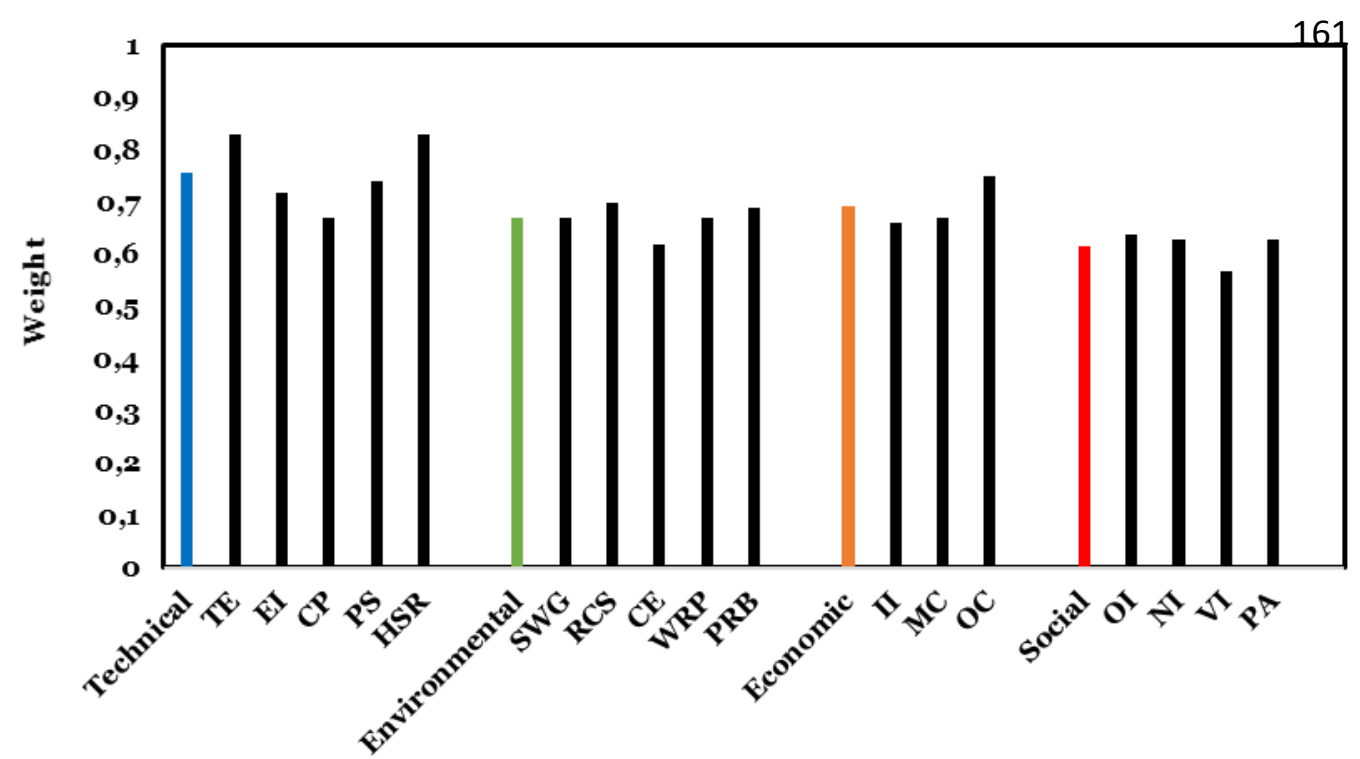

Criteria and respective sub-criteria 
Fig. 1. Calculated weights of the criteria and sub-criteria, measured as the average of the respective sub-criteria. The results indicate that technical criteria are most important for selecting the most sustainable industrial effluents treatment technologies. Economic criteria are in the second position of importance followed by environmental and social parameters. In addition, treatment efficiency, health and safety risks are the most important parameters among the influencing criteria. The abbreviations are described in Table 4.

Economic criteria, i.e., initial investments, maintenance and operation costs have received the next importance among the studied criteria. For many industries, which need to comply with stringent environmental regulations, there is currently a declining and competitive market for their product [1]. This reflects the importance of economic considerations for the treatment of industrial effluents such as biowastes. However, the potential of water reuse as well as other environmental factors are of relatively high importance as also expressed by the participating experts. There are some factors determining the quality of treated water for reuse such as efficiency of the applied treatment methods and additives, which are normally added to the wastewater sources during the treatment process and extraction of by-products from the effluents.

The emission of $\mathrm{CO}_{2}$ is an important environmental issue. The $\mathrm{CO}_{2}$ emission (CE) has received the least importance among the studied environmental criteria. However, considering the values presented in Table 4, the weight of this criterion (o.62) is above the fair (see Table 2) and this should be considered in the decision-making process. In this regard, those methods with the ability to control emission of greenhouse gases and those in which the treatment process is conducted via mechanisms leading to the production of end products other than $\mathrm{CO}_{2}$ (e.g., methane), can be more environmentally-friendly, and are better accepted.

The values of the most environmental sub-criteria are close to the economic sub-criteria, while the average weights of social criteria received the least importance among the main categories (table 4 and figure 1). This reflects the higher importance of both environmental and economic criteria in the experts' points of view as compared to social criteria. Furthermore, the fact that the importance of both environmental and economic criteria is similar indicates that nowadays pollution issues are as important as economic aspects related mainly to initial investment, operating and maintenance costs. Regarding the social criteria, their weights evidence the need to be considered when selecting the most appropriate treatment alternatives. 
The main improvement opportunities of some of the most widely used treatment alternatives for industrial effluents will be discussed here.

\subsection{Ranking the treatment technologies}

Various physico-chemical treatment methods have so far been applied for the treatment of industrial effluents such as biowastes. Coagulation and precipitation, membrane technologies, adsorption and oxidation processes are among the most effective and widely accepted techniques. Biological treatments, used as a single treatment or in combination with other physico-chemical methods have also been widely explored for the treatment of industrial effluents [13]. Although they have a number of advantages, including being eco-friendly and cost-effective, they exhibit lack of efficiency for the removal of recalcitrant biowastes due to their low biodegradability in highly polluted industrial effluents. However, scientific efforts are in progress to promote their efficiency for such applications. Pond systems, aerated lagoons, activated sludge and anaerobic sludge blanket technologies are the main biological treatments that have been applied so far for the treatment of industrial effluents around the world. The results of fuzzy-Delphi method for the investigated physicochemical and biological treatment methods are summarized in Tables 5 and 6, respectively. As summarized in Table 5, the most sustainable physico-chemical method for the treatment of industrial effluents is membrane-based technologies followed by adsorption, oxidation with nanomaterials and Fenton process. Membrane-based technologies have gained the highest scores in technical criteria (2.79) as well as in environmental criteria (2.27), while those of adsorption-based technologies are the most efficient in terms of economic and social criteria. However, considering all criteria, membranebased technologies have been identified as the most sustainable technology to deal with industrial effluents. Therefore, it can be highly correlated with the advances in the fabrication of novel membrane structures, mainly inorganic membranes (ceramic) and those decorated with engineered nanomaterials to increase the treatment efficiency and to decrease the fouling properties of the membranes [28]. 


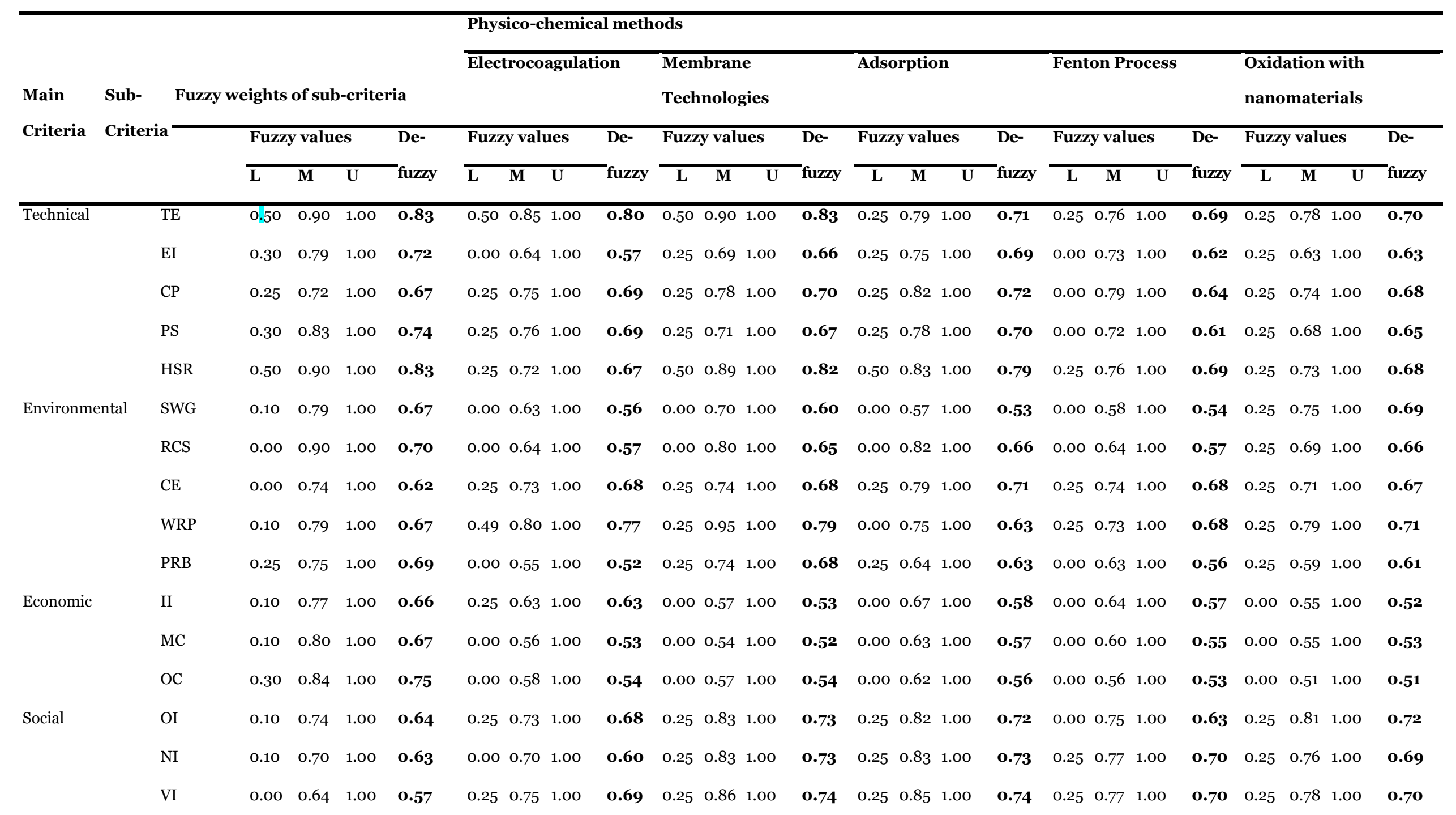




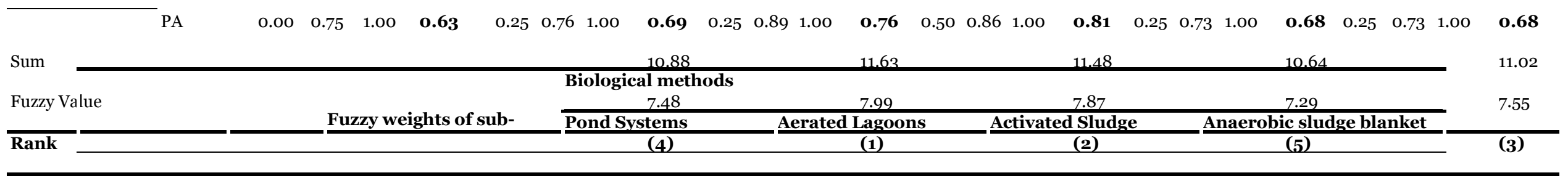

Table 5. The average fuzzy values and de-fuzzy numbers allocated by the experts to the studied physico-chemical methods.

Table 6. The average fuzzy values and de-fuzzy numbers allocated by the experts to the studied biological methods 


\begin{tabular}{|c|c|c|c|c|c|c|c|c|c|c|c|c|c|c|c|c|c|c|c|c|c|}
\hline \multirow[t]{3}{*}{ Main Criteria } & \multirow{3}{*}{$\begin{array}{l}\text { Sub- } \\
\text { Criteria }\end{array}$} & \multicolumn{16}{|c|}{ criteria } & \multicolumn{4}{|c|}{ technologies } \\
\hline & & \multicolumn{3}{|c|}{$\overline{\text { Fuzzy values }}$} & \multicolumn{4}{|c|}{ De-fuzzy Fuzzy values } & \multirow{2}{*}{$\begin{array}{l}\text { De- } \\
\text { fuzzy }\end{array}$} & \multicolumn{3}{|c|}{ Fuzzy values } & \multirow{2}{*}{$\begin{array}{l}\text { De- } \\
\text { fuzzy }\end{array}$} & \multicolumn{3}{|c|}{ Fuzzy values } & \multirow{2}{*}{$\begin{array}{c}\text { De- } \\
- \text { fuzzy }\end{array}$} & \multicolumn{3}{|c|}{ Fuzzy values } & \multirow[t]{2}{*}{$\overline{\text { De-fuzzy }}$} \\
\hline & & $\overline{\mathbf{L}}$ & $\overline{\mathbf{M}}$ & $\overline{\mathbf{U}}$ & & $\overline{\mathbf{L}}$ & $\overline{\mathbf{M}}$ & $\overline{\mathbf{U}}$ & & $\overline{\mathbf{L}}$ & $\overline{\mathbf{M}}$ & $\overline{\mathbf{U}}$ & & $\overline{\mathbf{L}}$ & $\overline{\mathbf{M}}$ & $\overline{\mathbf{U}}$ & & $\overline{\mathbf{L}}$ & $\overline{\mathbf{M}}$ & $\overline{\mathbf{U}}$ & \\
\hline \multirow[t]{5}{*}{ Technical } & $\mathrm{TE}$ & 0.50 & 0.90 & 1.00 & 0.83 & 0.00 & 0.58 & 1.00 & 0.54 & 0.25 & 0.68 & 1.00 & 0.65 & 0.25 & 0.76 & 1.00 & 0.69 & 0.25 & 0.63 & 1.00 & 0.63 \\
\hline & EI & 0.30 & 0.79 & 1.00 & 0.72 & 0.25 & 0.75 & 1.00 & 0.69 & 0.25 & 0.72 & 1.00 & 0.67 & 0.25 & 0.73 & 1.00 & 0.68 & 0.00 & 0.60 & 1.00 & 0.55 \\
\hline & $\mathrm{CP}$ & 0.25 & 0.72 & 1.00 & 0.67 & 0.25 & 0.63 & 1.00 & 0.63 & 0.25 & 0.66 & 1.00 & 0.64 & 0.25 & 0.73 & 1.00 & 0.68 & 0.00 & 0.65 & 1.00 & 0.58 \\
\hline & PS & 0.30 & 0.83 & 1.00 & 0.74 & 0.00 & 0.64 & 1.00 & $\mathbf{0 . 5 7}$ & 0.25 & 0.70 & 1.00 & 0.66 & 0.25 & 0.68 & 1.00 & 0.65 & 0.00 & 0.60 & 1.00 & 0.55 \\
\hline & HSR & 0.50 & 0.90 & 1.00 & $\mathbf{0 . 8 3}$ & 0.00 & 0.65 & 1.00 & 0.58 & 0.00 & 0.63 & 1.00 & 0.57 & 0.00 & 0.64 & 1.00 & $\mathbf{0 . 5 7}$ & 0.25 & 0.60 & 1.00 & 0.61 \\
\hline \multirow[t]{5}{*}{ Environmental } & SWG & 0.10 & 0.79 & 1.00 & 0.67 & 0.00 & 0.53 & 1.00 & 0.52 & 0.00 & 0.55 & 1.00 & 0.52 & 0.00 & 0.51 & 1.00 & 0.51 & 0.00 & 0.63 & 1.00 & 0.57 \\
\hline & RCS & 0.00 & 0.90 & 1.00 & 0.70 & 0.00 & 0.59 & 1.00 & 0.55 & 0.25 & 0.58 & 1.00 & 0.60 & 0.00 & 0.65 & 1.00 & 0.58 & 0.00 & 0.63 & 1.00 & $\mathbf{0 . 5 7}$ \\
\hline & $\mathrm{CE}$ & 0.00 & 0.74 & 1.00 & 0.62 & 0.00 & 0.47 & 1.00 & 0.48 & 0.00 & 0.45 & 1.00 & 0.47 & 0.00 & 0.54 & 1.00 & 0.52 & 0.00 & 0.58 & 1.00 & 0.54 \\
\hline & WRP & 0.10 & 0.79 & 1.00 & 0.67 & 0.00 & 0.52 & 1.00 & 0.51 & 0.00 & 0.59 & 1.00 & 0.54 & 0.00 & 0.68 & 1.00 & 0.59 & 0.00 & 0.55 & 1.00 & 0.53 \\
\hline & PRB & 0.25 & 0.75 & 1.00 & 0.69 & 0.00 & 0.47 & 1.00 & 0.48 & 0.00 & 0.44 & 1.00 & 0.47 & 0.00 & 0.59 & 1.00 & 0.54 & 0.00 & 0.79 & 1.00 & 0.64 \\
\hline \multirow[t]{3}{*}{ Economic } & II & 0.10 & 0.77 & 1.00 & 0.66 & 0.00 & 0.67 & 1.00 & 0.58 & 0.00 & 0.68 & 1.00 & 0.59 & 0.00 & 0.64 & 1.00 & $\mathbf{0 . 5 7}$ & 0.00 & 0.57 & 1.00 & 0.54 \\
\hline & MC & 0.10 & 0.80 & 1.00 & 0.67 & 0.00 & 0.72 & 1.00 & 0.61 & 0.00 & 0.59 & 1.00 & 0.55 & 0.00 & 0.62 & 1.00 & 0.56 & 0.00 & 0.68 & 1.00 & 0.59 \\
\hline & $\mathrm{OC}$ & 0.30 & 0.84 & 1.00 & 0.75 & 0.25 & 0.79 & 1.00 & 0.71 & 0.00 & 0.58 & 1.00 & 0.54 & 0.00 & 0.58 & 1.00 & 0.54 & 0.25 & 0.74 & 1.00 & 0.68 \\
\hline \multirow[t]{4}{*}{ Social } & OI & 0.10 & 0.74 & 1.00 & 0.64 & 0.00 & 0.37 & 1.00 & 0.43 & 0.00 & 0.38 & 1.00 & 0.44 & 0.00 & 0.44 & 1.00 & 0.47 & 0.00 & 0.48 & 1.00 & 0.49 \\
\hline & NI & 0.10 & 0.70 & 1.00 & 0.63 & 0.00 & 0.61 & 1.00 & 0.56 & 0.00 & 0.46 & 1.00 & 0.48 & 0.00 & 0.54 & 1.00 & 0.52 & 0.25 & 0.69 & 1.00 & 0.66 \\
\hline & VI & 0.00 & 0.64 & 1.00 & 0.57 & 0.00 & 0.44 & 1.00 & 0.47 & 0.00 & 0.49 & 1.00 & 0.49 & 0.00 & 0.52 & 1.00 & 0.51 & 0.00 & 0.65 & 1.00 & $\mathbf{0 . 5 7}$ \\
\hline & PA & 0.00 & 0.75 & 1.00 & 0.63 & 0.00 & 0.52 & 1.00 & 0.51 & 0.00 & 0.61 & 1.00 & 0.55 & 0.00 & 0.65 & 1.00 & $\mathbf{0 . 5 7}$ & 0.25 & 0.63 & 1.00 & 0.63 \\
\hline Sum & & & & & & & & & 9.42 & & & & 9.43 & & & & 9.75 & & & & 9.93 \\
\hline
\end{tabular}


Fuzzy Value

6.50

6.54 
Novel technologies such as advanced oxidation with nanomaterials are also moderately sustainable due to some existing barriers, which needs to be overcome[29]. Due to high potential of such technologies to satisfy the future needs for clean water resources, more efforts are required, especially in terms of economic (i.e., operating cost) and social considerations (i.e., social acceptance) to push these technologies for commercialization. In this sense, development of cheaper nanomaterials with the ability to be recovered and re-used and with also low toxic effects [30], are highly welcome as a strategic key for the development of advanced oxidation technologies with nanomaterials. Fenton-based technologies have also suffered from the weaknesses such as the release of relatively high amounts of chemicals. Development of facilities to recover chemicals before discarding would push up this technology by reducing both subsequent environmental risks and operating costs.

Among the biological treatment methods (Table 6) activated sludge has been identified as the most promising technology in terms of technical criteria (score: 2.47). However, considering all criteria (i.e. technical, environmental, economic and social), anaerobic sludge blanket was identified as the most sustainable technology (overall score: 6.82). This technology has gained the highest score in environmental criteria (1.90) compared to other studied biological technologies. It means that anaerobic sludge blanket is a green biological technique to deal with industrial effluents. It has also achieved the highest score (1.45) in social criteria, which would indicate that this technology may be selected as a socially acceptable technique. In addition, while pond systems are the most economic biological technique (score: 1.32), it cannot be selected as the most sustainable technology for the treatment of industrial effluents. It can clearly reflect the fact that considering all the sustainability criteria can highly affect the decision-making process to identify the most sustainable technology to deal with biowaste mitigation.

Furthermore, biological treatment methods are not generally sufficient enough to deal with recalcitrant biowastes such as adsorbable organic halides (AOXs). The effluents with high loads of such environmental contaminants may decrease the performance of such systems and even causing their failure. In order to overcome this issue, a combination of biological methods, as post-treatment, with oxidation with nanomaterials may be an alternative approach. However, published reports are quite rare on such combinations, which need more efforts to make the 
treatment methods more sustainable to deal with biowaste containing recalcitrant and toxic compounds.

\subsection{Development opportunities}

According to the results achieved, the main potentials for improvement of each method are briefly presented and discussed in the following sections.

\subsubsection{Physico-chemical methods}

Currently, membrane technologies are still the leading wastewater treatment methods to overcome global water pollution challenges[28]. Besides the high treatment efficiency of these technologies [31], they can contribute to the recovery of organics [32] and inorganic compounds $[30,31]$ present in the effluents. However, as it can be seen in Table 5, the operating cost (0.54) is still the main obstacle of the wider application of this method. Recent studies have mainly focused on the development of polymeric and inorganic (ceramic) membranes. Goh and Ismail [28] reviewed the latest progress in the fabrication of a new class of inorganic nanostructures, i.e. ceramic membranes (such as metal oxide membranes, zeolite membranes, metal organic framework membranes), and carbon-based membranes (such as carbon nanotubes membranes, and graphene membranes) as the promising materials for industrial treatment purposes. They concluded that the operating cost is still the main barrier for rapid commercialization of new branches of membrane technologies. In this regard, reduction of production costs through the development and use of cheap raw materials and development of efficient and cost-effective fabrication methods for membranes can be considered to be interesting to study. There are some evidences for such approaches in the literature. For instance, Scheibler et al. [35] developed a ultrafiltration process composed of a low-cost multilayer $\gamma-\mathrm{Al}_{2} \mathrm{O}_{3}$ ceramic membrane for the pre-treatment of oily wastewater. Zhu et al. [36] prepared a titanium dioxide membrane supported onto mullite hollow fiber synthesized from industrial solid waste coal fly ash as a low-cost alternative for the treatment of oily effluent.

In addition to the operating costs associated with the membrane preparation, fouling is considered another bottleneck on the application of these technologies. Bagheri and Ahmad [37] reviewed fouling mitigation technologies to conclude that application of nanomaterials, electrical and mechanical methods, ultrasonic irradiation, and their combination with biological 
277 treatments (Fig. 2) can be considered as effective strategies to deal with this problem. However,

278 none of these methods has yet been used in full-scale technologies to prove their efficiency with

279 real industrial effluents. Table 7 represents the main advantages and disadvantages of various

280 physico-chemical treatment methods for the treatment of recalcitrant biowastes and mitigation

281 of emerging pollutants from the industrial effluents.

282 Table 7. Some literature reports on the advantages and disadvantages of the studied physico-chemical methods

\begin{tabular}{|c|c|c|c|}
\hline Method & Advantages & Disadvantages & Reference \\
\hline Electrocoagulation & $\begin{array}{l}\text { No need for chemical reagents. } \\
\text { Relatively low operating costs. } \\
\text { Low secondary pollution. } \\
\text { Low sludge generation. } \\
\text { No moving parts. }\end{array}$ & $\begin{array}{l}\text { Maintenance is required. } \\
\text { Electrode passivation occurs over } \\
\text { time. } \\
\text { High water conductivity is required. } \\
\text { The lack of reactor systematic design }\end{array}$ & {$[38]$} \\
\hline $\begin{array}{l}\text { Membrane } \\
\text { technologies }\end{array}$ & $\begin{array}{l}\text { High treatment efficiency. } \\
\text { Small footprint. } \\
\text { High potential of the treated water to be } \\
\text { re-used. } \\
\text { Ease of implementation. } \\
\text { Fast start-up. }\end{array}$ & $\begin{array}{l}\text { Process stability due to membrane } \\
\text { fouling. } \\
\text { Relatively high operating costs. }\end{array}$ & $\begin{array}{l}{[26,39-} \\
41]\end{array}$ \\
\hline Fenton Process & $\begin{array}{l}\text { High treatment efficiency. } \\
\text { Non-selectivity. } \\
\text { No need for especial reactor } \\
\text { configuration (especially in case of non- } \\
\text { UV irradiated systems. }\end{array}$ & $\begin{array}{l}\text { Secondary pollution which requires } \\
\text { additional treatments. } \\
\text { Relatively high operating costs. }\end{array}$ & {$[42-44]$} \\
\hline $\begin{array}{l}\text { Oxidation with } \\
\text { engineered } \\
\text { nanomaterials }\end{array}$ & $\begin{array}{l}\text { High treatment efficiency. } \\
\text { Non-selectivity. } \\
\text { Low operating costs for some types of } \\
\text { ENMs. } \\
\text { No need for complicated reactor } \\
\text { configurations. } \\
\text { Ease of implementation. } \\
\text { Stability of the process. }\end{array}$ & $\begin{array}{l}\text { Probable secondary health and } \\
\text { safety risks. } \\
\text { Availability of some efficient } \\
\text { nanomaterials and nano-composites } \\
\text { in the current market. }\end{array}$ & {$\left[45^{-47}\right]$} \\
\hline Adsorption & $\begin{array}{l}\text { High treatment efficiency. } \\
\text { The potential of material recovery. } \\
\text { Ease of implementation. } \\
\text { Process stability. }\end{array}$ & $\begin{array}{l}\text { Relatively high treatment costs. } \\
\text { Selective removal of the } \\
\text { contaminants. } \\
\text { High sludge generation. }\end{array}$ & {$[48-50]$} \\
\hline
\end{tabular}




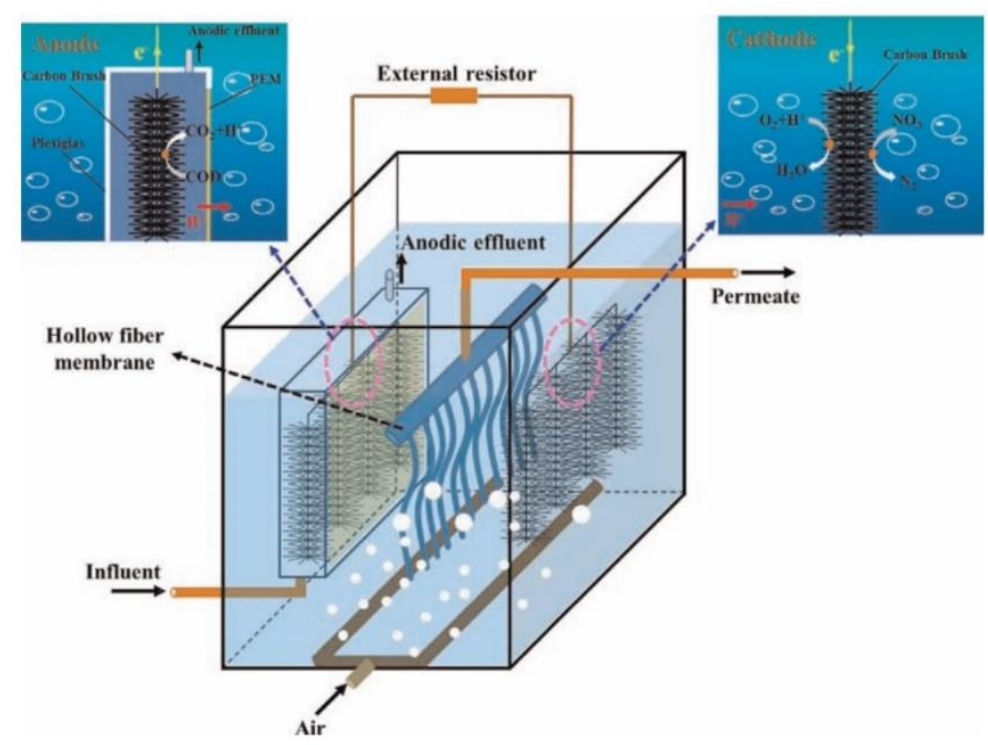

Fig. 2. A schematic of an in-situ integration of microbial fuel cell with hollow-fiber membrane bioreactor in order for treatment of wastewaters. Such a combinaion is also very effective for the mitigation of the membrane fouling due to thebiological decomposition of organic compounds responsible for the membrane fouling, reprinted with permission from Tian et al., 2015 [51].

Adsorption has also been widely studied as one of the most efficient and effective treatment technologies [52], easy to operate and well-suited for materials and nutrients recycling [53]. However, some environmental drawbacks related to solid waste generation (see Table 5) can hinder the promotion of adsorption to deal with the industrial effluents. Activated carbon is a widely used material for this process. However, such a conventional material is very expensive, especially for high quality products [54]. Hence, finding low-cost alternatives has been the subject of a number of recent studies. For instance, Castro et al. [55] indicated that application of cork granules is a cheap material for the treatment of textile effluents. Especially, the operating costs will significantly increase when a highly polluted effluent is subjected to treatment. For instance, Wang et al. [56] used combination of adsorption (wooden activated carbon) at a dosage of $10 \mathrm{~g} / \mathrm{L}$, and $1500 \mathrm{mg} / \mathrm{L}$ of polymeric magnesium ferric sulfate for subsequent coagulation process. This combination increased significantly the efficiency of the system to treat highly polluted effluents. This possibility derived from activated carbon (AC) can be economically beneficial compared to conventional AC processes.

Agriculture wastes have also been studied as the economic alternative material to be used in the treatment of industrial effluents. As an example, acid-washed coconut shell-based activated carbon (CSAC) has been used successfully for the treatment of palm oil mill effluents [56]. Bello et al. [54] used banana pseudo-stem, a plant waste of banana, as a cheap source of cellulose for the removal of 
dyes from industrial effluents. In recent years, several nanostructured materials have also been developed for the adsorption of complex organic pollutants in the context of effluents treatment. For a nanomaterial to be used for adsorption applications, specific surface area is considered to be the determinant factor [47]. For instance, Heydartaemeh [52] prepared a nanocomposite $\left(\mathrm{Ni}_{\mathrm{X}} \mathrm{Zn} \mathrm{n}_{\mathrm{X}}-\mathrm{X}\right.$ $\mathrm{Fe}_{2} \mathrm{O}_{4}$ ) with a specific surface area of $120 \mathrm{~m}^{2} / \mathrm{g}$ having a maximum of $90 \%$ of green malachite adsorption after $120 \mathrm{~min}$. Being low-cost, this feature is a main advantage for these materials in terms of their application for industrial treatment purposes.

Advanced oxidation processes have been identified in recent years as efficient methods (see Table 5) to deal with recalcitrant biowastes. The generation of powerful hydroxyl radicals in the medium are the basis of advanced oxidation of recalcitrant pollutants. Fenton reactions and oxidation with engineered nanomaterials are the main processes based on the generation of hydroxyl radicals. The reaction between iron salts and hydrogen peroxide is the basis of Fenton process [57] and short reaction time is the main advantage of this process [58]. Photo-Fenton process using ultraviolet irradiation (UVI) offers higher removal efficiency compared to conventional Fenton process, although it may bring some safety issues and higher operating costs [59]. The main drawback of Fenton processes, however, is the generation of secondary pollutants by releasing ferric ion to the effluents [6o]. As a result, additional treatment is required, for instance, by precipitation of the ferric ions through the $\mathrm{pH}$ increase of the effluents [61]. This additional treatment may result in generating ironcontaining sludge, whose treatment would be expensive and needs a high amount of chemicals $[62,63]$.

In order to overcome these drawbacks, heterogeneous Fenton reactions based on the application of iron oxide nanomaterials or other types of inorganic nanomaterials such as titanium dioxide, copper-based nanomaterials, etc., have gained a huge attention in recent years $[27,62,63]$. However, the reaction kinetics of these processes are slower than those with Fenton process [60]. The properties of nanomaterials such as high specific surface area and agglomeration state may also play a critical role in nano-catalytic processes. The main mechanisms involved in the removal or degradation of the pollutants using nanomaterials consist on the chemisorption of the pollutants on the surface of the materials, transformation of hydrogen peroxide to hydroxyl radicals on the surface of the materials and decomposition of hydrogen peroxide to hydroxyl radicals onto the surface of the nanomaterials. 
can be seen in the literature for the synthesis of low-cost catalytic materials with the ability to work under visible light irradiation, for instance by introducing nitrogen into the structure of titanium dioxide nanomaterials, as one of the most widely applied nanomaterials for wastewater treatment [67]. In spite of the inherent advantages on the application of engineered nanomaterials for the treatment of industrial effluents such as biowastes, the subsequent health problems arising from the possible toxic effects of nanomaterials are now under much debate [66-69]. Although some in vitro and in vivo studies have shown that some types of the nanomaterials such copper oxide nanoparticles [47] can cause toxic effects on terrestrial and aquatic organisms, the probable health problems associated with the use of nanomaterials have not yet been widely investigated and understood.

Electrocoagulation has also been successfully applied in recent years for the treatment of a variety of pollutants in order to reduce parameters such as chemical oxygen demand (COD), color, recalcitrant compounds, etc., from the industrial effluents. The basis of coagulation process is to introduce metal salts to the stream in order to generate larger flocs from small particles. In the electrocoagulation process, metal cations are dissolved from the anode, resulting in simultaneous formation of hydroxide ions and hydrogen in the form of gas at the cathode $\left(\mathrm{Eq}_{\mathrm{s} .}\right.$ 5, 6).

$$
\mathrm{M}^{\mathrm{O}} \rightarrow \mathrm{M}^{\mathrm{n}+}+\mathrm{n} e^{-}
$$

Eq. 5

$$
\mathrm{nH}_{2} \mathrm{O}(l)+\mathrm{ne}^{-} \rightarrow \mathrm{nOH}^{-}+\frac{n}{2} \quad \mathrm{H}_{2}(\mathrm{~g})
$$

While in the conventional coagulation methods, coagulants such as aluminium chloride [72] are used, in the electrocoagulation process there is no need for any coagulant to be added to the effluents. Hence, the main advantage of this process is to mitigate the release of chemical substances into the treated effluent [73]. This method has been considered as an efficient solution for a sustainable industrial wastewater treatment. However, several parameters such as current density, operating $\mathrm{pH}$, electrolyte type and passivation, reactor design, etc., can determine its efficiency for the treatment of highly polluted industrial effluents. These factors can determine electrical energy requirement and operating costs including the costs of electrodes, electrode replacement, chemicals used for $\mathrm{pH}$ and electric conductivity adjustment, etc. Recently, some measures have been applied in order to reduce the operating costs of this process such as the use of Fe electrodes instead of other metals such as aluminium [13]. 
For electrocoagulation process to be more economic there is a need to increase the efficiency of the energy used in the system. For instance, Cheng-ChunHe et al. [74] indicated that chloride addition and ultrasonic processing can increase the energy efficiency of the system by removing the passivation layer on the electrodes used for electrocoagulation. Reducing the sludge generation in coagulation processes is another potential for improvement in the application of this technology. Considering that the cost of sludge disposal is remarkable [75], the related costs should be included in the design of the treatment facilities using electrocoagulation techniques. Hence, there is a greater need for more studies on the reduction of sludge volume in this technology.

\subsubsection{Biological treatments}

Stabilization ponds, as an artificial ecosystem, consist on the co-existence of different biological communities such as bacteria, protozoa, alga, fungi, and crustacean larvae. Generally, stabilization ponds are partially aerobic and partially anaerobic in a basin with a depth of about 1 to 2 meters. These systems have been used for the treatment of a variety of industrial effluents, especially in under developed countries. For instance, in Malaysia, stabilization ponds are the most widely used methods for the treatment of palm oil production mill effluents[76].In fact, they are good options when large land areas are available for such treatment installations. Although they have shown to some extent as the acceptable treatment efficiency, there are still some drawbacks in the application of these systems.

Large amounts of greenhouse gases such as carbon dioxide and methane are released from the open ponds into the atmosphere. In addition to the effects of these systems on the global warming, the recovery of energy in the form of methane gas is highly limited from such systems [75,76].Sia et al. [76] stated that by 2020 ponding systems in Malaysia will release 7.2 million tonnes of $\mathrm{CO}_{2}$ into the atmosphere. Although some measures such as application of photosynthetic bacteria to recover $\mathrm{CO}_{2}$ in the form of bacterial cell [79] have been adopted for capturing carbon dioxide, this problem is still considered as the major deficiency of these systems. The odor impact is another issue in pond systems though some studies are available in the literature to mitigate this problem. Truppel et al. [80] achieved a reduction of odor of a treatment plant located near a populated area by recirculation of the effluent followed by aeration of the pond. The combination of pond systems with other treatment facilities may also be considered as an effective solution to deal with this problem and also to increase the quality 
of the treated effluents. For instance, Liu et al. [81] used a combination of a pond system and a wetland to increase the overall efficiency of the system for the treatment of refractory organic pollutants in petrochemical industrial wastewater.

Aerated lagoons have also been extensively used for the treatment of industrial effluents such as kraft mill effluents [80, 81].These systems present acceptable performance for the removal of biological oxygen demand (BOD) from industrial effluents[13]. However, some studies have shown that their performance for the removal of color from the effluents is considered as one of the drawbacks of these systems. Also, energy input and daily maintenance costs are the main challenges of using these systems, which require the development of efficient aeration and mixing technologies with acceptable energy efficiency. However, by increasing the efficiency of the systems in order to promote biodegradation, the sludge accumulation will occur as one of the main disadvantages of such systems. These may lead to the increase of suspended biomass, which needs a final treatment such as filtration with an increase of further treatment cost.

Over the past decade, many industries have started upgrading their aerated lagoons to activated sludge systems due to the advantages of such systems [83]. Xavier et al. [83] compared the aerated lagoon with activated sludge processes to conclude that activated sludge system might present better efficiency for the treatment of kraft pulp and paper mill effluents, except for phenolic compounds.

In addition to the activated sludge processes, anaerobic sludge blanket processes are the most widely used anaerobic treatment methods in many industries[82, 83]. From Table 5, it is evident that although the treatment efficiency of activated sludge process has received a higher value (0.69) compared to that of the anaerobic sludge blanket technology (o.63), the latter technology was identified as the more sustainable one to deal with industrial effluents. It demonstrates the importance of other sustainability criteria to achieve a final decision to be adopted for an industrial wastewater treatment method. However, in spite of the acceptable performance of both the mentioned biological systems, these methods are now struggling with some certain disadvantages such as relatively high sludge production, especially in the case of activated sludge.

Although the degradation mechanism of the recalcitrant biowaste pollutants in anaerobic digestion processes leads to the formation of biogas (mainly methane), and thereby reducing the 
emission of greenhouse gases, they are sensitive to some inhibitory elements such as sulfide and toxic substances [86]. Considering that methane is an important greenhouse gas with potential 34-times higher than carbon dioxide, the production of this gas can significantly contribute to the emission of greenhouse gases. However, by using the produced gas as a source of energy, the anaerobic process can be more cost-effective when compared to activated sludge processes. However, the need for the supply of alkalinity may increase the energy consumption and greenhouse gases (GHGs) generation in anaerobic treatment process. The average alkalinity required in anaerobic processes is in the range of $2000-4000 \mathrm{mg} \mathrm{CaCO}_{3} / \mathrm{l}$ to maintain the neutral $\mathrm{pH}$. Hence, production and transportation of the required alkalinity agents can be considered as significant up-stream sources of $\mathrm{CO}_{2}$ emission [24].

\section{Conclusions}

The main objective of this study is to provide a framework for making sustainable decisions for selecting suitable wastewater treatment technologies considering the integration of multicriteria (technical, environmental, economic and social). The application of fuzzy-Delphi method indicated that technical criteria, especially treatment efficiency and health and safety risks in the treatment plant are the most important parameters among the studied criteria. The results also revealed that there are other criteria (i.e., technical, economic, environmental and social) that have enough significance to be also considered when deciding on the most suitable industrial effluent treatment technologies.

Overall, the results of this study demonstrate that selection of the treatment methods to deal with industrial effluents cannot strictly be based only on treatment efficiency to satisfy the requirements of sustainable development. Among the treatment methods, membrane-based technologies are identified as the most viable physico-chemical approaches for recalcitrant biowastes mitigation, whereas anaerobic sludge blanket technology can be the most sustainable biological method to deal with highly polluted industrial effluents containing biowastes. The opportunities for improvements of each treatment method have also been discussed while providing a general perspective for the future. In any case, biowastes mitigation is a formidable issue and membrane technologies combined with biological treatment processes appear to be the solution to this problem.

\section{Acknowledgments}


Aveiro Institute of Materials, FCT Ref. UID/CTM/50011/2019, financed by national SFRH/BD/103695/2014 for M. Kamali.

\section{References}

[1] M. Machani, M. Nourelfath, S. D’Amours, S. D'Amours, S. D'Amours, A mathematicallybased framework for evaluating the technical and economic potential of integrating

[4] G. Chhipi-Shrestha, K. Hewage, R. Sadiq, Fit-for-purpose wastewater treatment: Testing to implementation of decision support tool (II), Sci. Total Environ. 607-608 (2017)

[3] UNICEF-WHO, Updates Report of the WHO/UNICEF Joint Monitoring Programme for Water Supply and Sanitation. Available at:. http://www.unwater.org/publications/, 403-412. doi:10.1016/j.scitotenv.2017.06.268.

[5] M. Kamali, A.A. Alesheikh, S.A. Alavi Borazjani, A. Jahanshahi, Z. Khodaparast, M. Khalaj, Delphi-ahp and weighted index Overlay-GIS approaches for industrial site selection case study: Large extractive industrial units in Iran, J. Settlements Spat. Plan. 8 (2017). doi:10.24193/JSSP.2017.2.03. 
Eng. 2016 (2016). doi:10.1155/2016/5278716.

484 innovative treatment systems for sustainable dairy wastewater management, J. Clean. Prod. 112 (2016) 4605-4617. doi:10.1016/j.jclepro.2015.08.107.

[9] P.L. Chang, C.W. Hsu, P.C. Chang, Fuzzy Delphi method for evaluating hydrogen production technologies, Int. J. Hydrogen Energy. 36 (2011) 14172-14179. doi:10.1016/j.ijhydene.2011.05.045.

[10] Y.L. Hsu, C.H. Lee, V.B. Kreng, The application of Fuzzy Delphi Method and Fuzzy AHP in lubricant regenerative technology selection, Expert Syst. Appl. 37 (2010) 419-425. doi:10.1016/j.eswa.2009.05.068.

[11] F. Tahriri, M. Mousavi, The application of fuzzy Delphi and fuzzy inference system in supplier ranking and selection, J. Ind. Eng. Int. 10 (2014) 66. doi:10.1007/s40092-014oo66-6.

[12] A.P. Sánchez-lezama, J. Cavazos-arroyo, Applying the Fuzzy Delphi method for determining socio-ecological factors that influence adherence to mammography screening in rural areas of Mexico, Cad. Saúde Pública Vol.3o No.2 Rio Janeiro. 30 (2014) 245-258. doi:10.1590/0102-311Xooo25113.

[13] M. Kamali, Z. Khodaparast, Review on recent developments on pulp and paper mill wastewater treatment, Ecotoxicol. Environ. Saf. 114 (2015) 326-342. doi:10.1016/j.ecoenv.2014.05.005.

[14] A. Jahanshahi, M. Kamali, M. Khalaj, Z. Khodaparast, Delphi-based prioritization of economic criteria for development of wave and tidal energy technologies, Energy. 167 (2019) 819-827. doi:10.1016/j.energy.2018.11.040.

[15] T. Belton, Valerie, Stewart, Multiple criteria decision analysis, an integrated approach, Springer Berlin Heidelberg, 2002.

[16] M. Kamali, S. D.P., M.E. V. Costa, I. Capela, T.M. Aminabhavi, Sustainability considerations in membrane-based technologies for industrial effluents treatment, Chem. Eng. J. in press (2019). 
511 [17] M. Dursun, A fuzzy approach for the assessment of wastewater treatment alternatives, Eng. Lett. 24 (2016) 231-236.

513

514

515

516

517

518

519

520

521

522

523

524

525

526

527

528

529

530

531

[18] X. Ouyang, F. Guo, D. Shan, H. Yu, J. Wang, Development of the integrated fuzzy analytical hierarchy process with multidimensional scaling in selection of natural wastewater treatment alternatives, Ecol. Eng. $74 \quad$ (2015) 438-447. doi:10.1016/j.ecoleng.2014.11.006.

[19] A.I. Ban, L. Coroianu, Nearest interval , triangular and trapezoidal approximation of a fuzzy number preserving ambiguity, Int. J. Approx. Reason. 53 (2012) 805-836. doi:10.1016/j.ijar.2012.02.001.

[20] A.N. Gani, S.N.M. Assarudeen, A new operation on triangular fuzzy number for solving fuzzy linear programming problem, Appl. Math. Sci. 6 (2012) 525-532. doi:10.13140/2.1.3405.8881.

[21] C. Cheng, Y. Lin, Evaluating the best main battle tank using fuzzy decision theory.pdf, Eur. J. Oper. Res. 142 (2002) 174-186.

[22] H.C. Chu, G.J. Hwang, A Delphi-based approach to developing expert systems with the cooperation of multiple experts, Expert Syst. Appl. 34 (2008) 2826-2840. doi:10.1016/j.eswa.2007.05.034.

[23] Y.L. Hsu, C.H. Lee, V.B. Kreng, The application of Fuzzy Delphi Method and Fuzzy AHP in lubricant regenerative technology selection, Expert Syst. Appl. 37 (2010) 419-425. doi:10.1016/j.eswa.2009.05.068.

[24] O. Ashra, L. Yerushalmi, F. Haghighat, Wastewater treatment in the pulp-and-paper industry: A review of treatment processes and the associated greenhouse gas emission, J. Environ. Manage. 158 (2015) 146-157. doi:10.1016/j.jenvman.2015.05.010.

[25] J. Mata-Alvarez, J. Dosta, M.S. Romero-Güiza, X. Fonoll, M. Peces, S. Astals, A critical review on anaerobic co-digestion achievements between 2010 and 2013, Renew. Sustain. Energy Rev. 36 (2014) 412-427. doi:10.1016/j.rser.2014.04.039.

[26] H. Ozgun, R. Kaan, M. Evren, C. Kinaci, H. Spanjers, J.B. Van Lier, A review of anaerobic membrane bioreactors for municipal wastewater treatment: Integration options , 
limitations and expectations, Sep. Purif. Technol. 118 (2013) 89-104. doi:10.1016/j.seppur.2013.06.036.

[27] V. Khandegar, A.K. Saroha, Electrocoagulation for the treatment of textile industry effluent-a review., J. Environ. Manage. 128 (2013) 949-63. doi:10.1016/j.jenvman.2013.06.043.

[28] P.S. Goh, A.F. Ismail, A review on inorganic membranes for desalination and wastewater treatment, Desalination. 434 (2018) 60-80. doi:10.1016/j.desal.2017.07.023.

[29] M. Kamali, K.M. Persson, M.E. Costa, I. Capela, Sustainability criteria for assessing

[30] M. Kamali, M.E. V. Costa, G. Otero-Irurueta, I. Capela, Ultrasonic irradiation as a green production route for coupling crystallinity and high specific surface area in iron nanomaterials, J. Clean. Prod. 211 (2018) 185-197. doi:10.1016/j.jclepro.2018.11.127.

[33] T. Yan, Y. Ye, H. Ma, Y. Zhang, W. Guo, B. Du, Q. Wei, D. Wei, H.H. Ngo, A critical

[34] S. Daguerre-martini, M.B. Vanotti, M. Rodriguez-pastor, A. Rosal, R. Moral, Nitrogen recovery from wastewater using gas-permeable membranes: Impact of inorganic carbon content and natural organic matter, Water Res. 137 (2018) 201-210. doi:10.1016/j.watres.2018.03.013. 
Performance of zeolite membrane (ZSM-5/ $/$-Alumina) in the oil/water separation process, Desalin. Water Treat. 56 (2015) 3561-3567.

[36] L. Zhu, M. Chen, Y. Dong, C.Y. Tang, A. Huang, A low-cost mullite-titania composite ceramic hollow fi ber micro fi ltration membrane for highly ef fi cient separation of oilin- water emulsion, Water Res. 90 (2016) 277-285. doi:10.1016/j.watres.2015.12.035.

[37] M. Bagheri, S. Ahmad, Critical review of fouling mitigation strategies in membrane bioreactors treating water and wastewater, Bioresour. Technol. 258 (2018) 318-334. doi:10.1016/j.biortech.2018.03.026.

[39] G. Skouteris, D. Hermosilla, P. López, C. Negro, Á. Blanco, Anaerobic membrane bioreactors for wastewater treatment: A review, Chem. Eng. J. 198-199 (2012) 138-148.

[40] Y. Hu, X.C. Wang, H.H. Ngo, Q. Sun, Y. Yang, Anaerobic dynamic membrane bioreactor

[42] A. Babuponnusami, K. Muthukumar, A review on Fenton and improvements to the

[44] A.D. Bokare, W. Choi, Review of iron-free Fenton-like systems for activating H2O2in (AnDMBR) for wastewater treatment: A review, Bioresour. Technol. 247 (2018) 11071118. doi:10.1016/j.biortech.2017.09.101.

[41] A.N.L. Ng, A.S. Kim, A mini-review of modeling studies on membrane bioreactor (MBR) treatment for municipal wastewaters, Desalination. 212 (2007) 261-281. doi:10.1016/j.desal.2006.10.013. Fenton process for wastewater treatment, J. Environ. Chem. Eng. 2 (2014) 557-572. doi:10.1016/j.jece.2013.10.011.

[43] N. Wang, T. Zheng, G. Zhang, P. Wang, A review on Fenton-like processes for organic wastewater treatment, J. Environ. Chem. Eng. 4 (2016) 762-787. doi:10.1016/j.jece.2015.12.016. advanced oxidation processes, J. Hazard. Mater. 275 (2014) 121-135. 
[45] M. Anjum, R. Miandad, M. Waqas, F. Gehany, M.A. Barakat, Remediation of wastewater using various nano-materials, Arab. J. Chem. (2016). doi:10.1016/j.arabjc.2016.10.004.

[46] R.C. Olvera, S.L. Silva, E. Robles-Belmont, E.Z. Lau, Review of nanotechnology value chain for water treatment applications in Mexico, Resour. Technol. 3 (2017) 1-11. doi:10.1016/j.reffit.2017.01.008.

[47] M. Khalaj, M. Kamali, Z. Khodaparast, A. Jahanshahi, Copper-based nanomaterials for environmental decontamination - An overview on technical and toxicological aspects, Ecotoxicol. Environ. Saf. 148 (2018) 813-824. doi:10.1016/j.ecoenv.2017.11.060.

[48] K.B. Tan, M. Vakili, B.A. Horri, P.E. Poh, A.Z. Abdullah, B. Salamatinia, Adsorption of dyes by nanomaterials: Recent developments and adsorption mechanisms, Sep. Purif. Technol. 150 (2015) 229-242. doi:10.1016/j.seppur.2015.07.009.

[49] M. Kamali, A.P.D. Gomes, Z. Khodaparast, T. Seifi, Review on recent advances in environmental remediation and related toxicity of engineered nanoparticles, Environ. Eng. Manag. J. 15 (2016) 923-934.

[50] O.Y. Bakather, A.K. Fard, M. Khraisheh, M.S. Nasser, M.A. Atieh, Enhanced Adsorption of Selenium Ions from Aqueous Solution Using Iron Oxide Impregnated Carbon Nanotubes, 2017 (2017). doi:10.1155/2017/4323619.

[51] Y. Tian, H. Li, L. Li, X. Su, Y. Lu, W. Zuo, J. Zhang, In-situ integration of microbial fuel cell with hollow- fi ber membrane bioreactor for wastewater treatment and membrane fouling mitigation, Biosens. Bioelectron. $64 \quad$ (2015) 189-195. doi:10.1016/j.bios.2014.08.070.

[52] M.R. Heydartaemeh, An innovative application of (NiXZnX-X Fe2O4) Mineral nanoparticles for adsorption of Malachite green dye from wastewater effluents, J. Min. Environ. 9 (2018) 143-152. doi:10.22044/jme.2017.5858.1397.

[53] Q. Lin, M. Gao, J. Chang, H. Ma, Adsorption properties of crosslinking carboxymethyl cellulose grafting dimethyldiallylammonium chloride for cationic and anionic dyes, Carbohydr. Polym. 151 (2016) 283-294. doi:10.1016/j.carbpol.2016.05.064. 
[54] K. Bello, B. Kunhanna, B. Narayana, A. Rao, A study on adsorption behavior of newly synthesized banana pseudo-stem derived superabsorbent hydrogels for cationic and anionic dye removal from e ffl uents, Carbohydr. Polym. 181 (2018) 605-615. doi:10.1016/j.carbpol.2017.11.106.

[55] M. Castro, V. Nogueira, I. Lopes, M.N. Vieira, T. Rocha-Santos, R. Pereira, Treatment of a textile effluent by adsorption with cork granules and titanium dioxide nanomaterial, $\mathrm{J}$. Environ. Sci. Heal. - Part A Toxic/Hazardous Subst. Environ. Eng. 53 (2018) 524-536. doi:10.1080/10934529.2018.1425020.

[56] B. Wang, Y. Shui, H. Ren, M. He, Research of combined adsorption-coagulation process in treating petroleum refinery effluent, Environ. Technol. 38 (2017) 456-466. doi:10.1080/09593330.2016.1197319.

[57] M. Hartmann, H. Keller, Wastewater treatment with heterogeneous Fenton-type catalysts based on porous materials, J. Mater. Chem. 20 (2010) 9002-9017. doi:10.1039/cojmoo577k.

[58] O. Koba, L. Biro, Fenton-like reaction: a possible way to efficiently remove illicit drugs and pharmaceuticals from wastewater, Environ. Toxicol. Pharmacol. 9 (2015) 483-488. doi:10.1016/j.etap.2014.12.016.

[59] J. Herney-ramirez, M.A. Vicente, L.M. Madeira, Heterogeneous photo-Fenton oxidation with pillared clay-based catalysts for wastewater treatment: A review, Appl. Catal. B, Environ. 98 (2010) 10-26. doi:10.1016/j.apcatb.2010.05.004.

[6o] O. Sze, N. Sum, J. Feng, X. Hu, P. Lock, Photo-assisted fenton mineralization of an azodye acid black 1 using a modified laponite clay-based $\mathrm{Fe}$ nanocomposite as a heterogeneous catalyst, Top. Catal. 33 (2005) 233-242. doi:10.1007/s11244-005-2532-2.

[61] C. Kuan, S. Chang, S.L.M. Schroeder, Fenton-Like Oxidation of 4-Chlorophenol: Homogeneous or Heterogeneous?, Ind. Eng. Chem. Res. 54 (2015) 8122-8129. doi:10.1021/acs.iecr.5bo2378.

[62] M.L. Rache, A.R. García, H.R. Zea, A.M.T. Silva, L.M. Madeirac, J.H. Ramíreza, Azo-dye orange II degradation by the heterogeneous Fenton- like process using a zeolite Y-Fe 

catalyst - Kinetics with a model based on the Fermi' s equation, Appl. Catal. B Environ. 146 (2014) 192-200. doi:10.1016/j.apcatb.2013.04.028.

[63] A. Mirzaei, Z. Chen, F. Haghighat, L. Yerushalmi, Removal of pharmaceuticals from water by homo heterogonous Fenton-type processes - A review, Chemosphere. 174 (2017) 665-688. doi:10.1016/j.chemosphere.2017.02.019.

[64] M. Kamali, I. Capela, M.E. Costa, Ultrasonic Synthesis of Zero Valent Iron Nanoparticles for the Efficient Discoloration of Aqueous Solutions Containing Methylene Blue Dye, in: S. Ul-Islam, B.S. Butola (Eds.), Nanomater. Wet Process. Text., Wiley, 2018: pp. 261284. doi:10.1002/9781119459804.ch8.

[65] M. Kamali, M.E. Costa, I. Capela, Nitrate Removal and Nitrogen Sequestration from Polluted Waters Using Zero-Valent Iron Nanoparticles Synthesized under Ultrasonic Irradiation, in: Adv. Mater. Wastewater Treat., John Wiley \& Sons, Inc., Hoboken, NJ, USA., 2017: pp. 479-505. doi:10.1002/9781119407805.ch13.

[66] S.R. Pouran, A.R.A. Aziz, W. Mohd, A. Wan, Journal of Industrial and Engineering Chemistry Review on the main advances in photo-Fenton oxidation system for recalcitrant wastewaters, J. Ind. Eng. Chem. $21 \quad$ (2015) 53-69. doi:10.1016/j.jiec.2014.05.005.

[67] R. Ramos, D. Scoca, R.B. Merlo, F.C. Marques, F. Alvarez, L.F. Zagonel, Study of nitrogen ion doping of titanium dioxide films, Appl. Soil Ecol. 443 (2018) 619-627. doi:10.1016/j.apsusc.2018.02.259.

[68] J. Hong, C.M. Rico, L. Zhao, A.S. Adeleye, A.A. Keller, J.R. Peralta-Videa, J.L. GardeaTorresdey, Toxic effects of copper-based nanoparticles or compounds to lettuce (Lactuca sativa) and alfalfa (Medicago sativa), Environ. Sci. Process. Impacts. 17 (2015) 177-185. doi:10.1039/C4EMoo551A.

[69] M. Ates, Z. Arslan, V. Demir, J. Daniels, I.O. Farah, Accumulation and Toxicity of CuO and ZnO Nanoparticles ThroughWaterborne and Dietary Exposure of Goldfish (Carassius auratus), Environ. Toxicol. 24 (2014) 119-128. doi:10.1002/tox.

[70] M. Koltowski, P. Oleszczuk, Effect of activated carbon or biochars on toxicity of different 
soils contaminated by mixture of native polycyclic aromatic hydrocarbons and heavy metals, Environ. Toxicol. Chem. 35 (2016) 1321-1328. doi:10.1002/etc.3246.

[71] F. Deng, S. Wang, H. Xin, Toxicity of $\mathrm{CuO}$ Nanoparticles to Structure and Metabolic Activity of Allium cepa Root Tips, Bull. Environ. Contam. Toxicol. 97 (2016) 702-708. doi:10.1007/s00128-016-1934-0.

[72] J.-P. Wang, Y. Chen, Y. Wang, S.-J. Yuan, H. Yu, Optimization of the coagulationflocculation process for pulp mill wastewater treatment using a combination of uniform design and response surface methodology, Water Res. 45 (2011) 5633-5640. doi:10.1016/j.watres.2011.08.023.

[73] I. Kabdaşlı, I. Arslan-Alaton, T. Ölmez-Hancı, O. Tünay, Electrocoagulation applications for industrial wastewaters: a critical review, Environ. Technol. Rev. 1 (2012) 2-45. doi:10.1080/21622515.2012.715390.

[74] Cheng-ChunHe, Ching-YaoHu, Shang-LienLo, Integrating chloride addition and ultrasonic processing with electrocoagulation to remove passivation layers and enhance phosphate removal, Sep. Purif. Technol. 201 (2018) 148-155. doi:10.1016/j.seppur.2018.03.011.

[75] Ö.Y. Balik, Serdar Aydin, Coagulation/flocculation optimization and sludge production for pre-treatment of paint industry wastewater, Desalin. Water Treat. 57 (2016) 1269212699. doi:10.1080/19443994.2015.1051125.

[76] Y.Y. Sia, I. Ai, W. Tan, M.O. Abdullah, Adsorption of colour, TSS and COD from palm oil mill effluent (POME) using acid-washed coconut shell activated carbon: Kinetic and mechanism studies, MATEC Web Conf. $87 \quad$ (2017) 03010. doi:10.1051/matecconf/20178703010.

[77] F. Schuchardt, K. Wulfert, T. Herawan, Effect of new palm oil mill processes on the EFB and POME utilization, J. Oil Palm Res. Special Is (2008) 115-126.

[78] Y. Shirai, M. Wakisaka, S. Yacob, A.L.I. Hassan, Reduction of methane released from palm oil mill lagoon in malaysia and its countermeasures, Mitig. Adapt. Strateg. Glob. Chang. 8 (2003) 237-252. 
[79] C. Chiemchaisri, L. Jaitrong, R. Honda, K. Fukushi, K. Yamamoto, Photosynthetic bacteria pond system with infra-red transmitting filter for the treatment and recovery of organic carbon from industrial wastewater, Water Sci. Technol. 56 (2007) 109-116. doi:10.2166/wst.2007.686.

[80] A. Truppel, J.L. Camargos, R.H. da Costa, P.B. Filho, Reduction of odors from a facultative pond using two different operating practices, Water Sci Technol. 51 (2005) 205-11. doi:10.2166/wst.2005.0463.

[81] S. Liu, Q. Ma, B. Wang, Advanced treatment of refractory organic pollutants in petrochemical industrial wastewater by bioactive enhanced ponds and wetland system, Ecotoxicology. 23 (2014) 689-698. doi:10.1007/s10646-014-1215-9.

[82] M. Belmonte, C. Xavier, J. Decap, M. Martinez, R. Sierra-alvarez, G. Vidal, Improved aerobic biodegradation of abietic acid in ECF bleached kraft mill effluent due to biomass adaptation, J. Hazard. Mater. 135 (2006) 256-263. doi:10.1016/j.jhazmat.2005.11.061.

[83] C.R. Xavier, A. Mosquera-corral, J. Becerra, V. Hernández, G. Vidal, Activated sludge versus aerated lagoon treatment of kraft mill effluents containing $\beta$-sitosterol and stigmasterol, J. Environ. Sci. Heal. Part A. 44 (2009) 327-335. doi:10.1080/10934520802659646.

[84] M.A. Hubbe, J.R. Metts, D. Hermosilla, M.A. Blanco, L. Yerushalmi, F. Haghighat, P. Lindholm-Lehto, Z. Khodaparast, M. Kamali, A. Elliott, Wastewater treatment and reclamation: A review of pulp and paper industry practices and opportunities, BioResources. 11 (2016). doi:10.1016/j.seppur.2011.07.002.

[85] T. Meyer, E.A. Edwards, Anaerobic digestion of pulp and paper mill wastewater and sludge., Water Res. 65 (2014) 321-349. doi:10.1016/j.watres.2014.07.022.

[86] M. Kamali, T.T. Gameiro, M.E.V. Costa, I. Capela, Anaerobic digestion of pulp and paper mill wastes - An overview of the developments and improvement opportunities, Chem. Eng. J. 298 (2016) 162-182. doi:10.1016/j.cej.2016.03.119. 


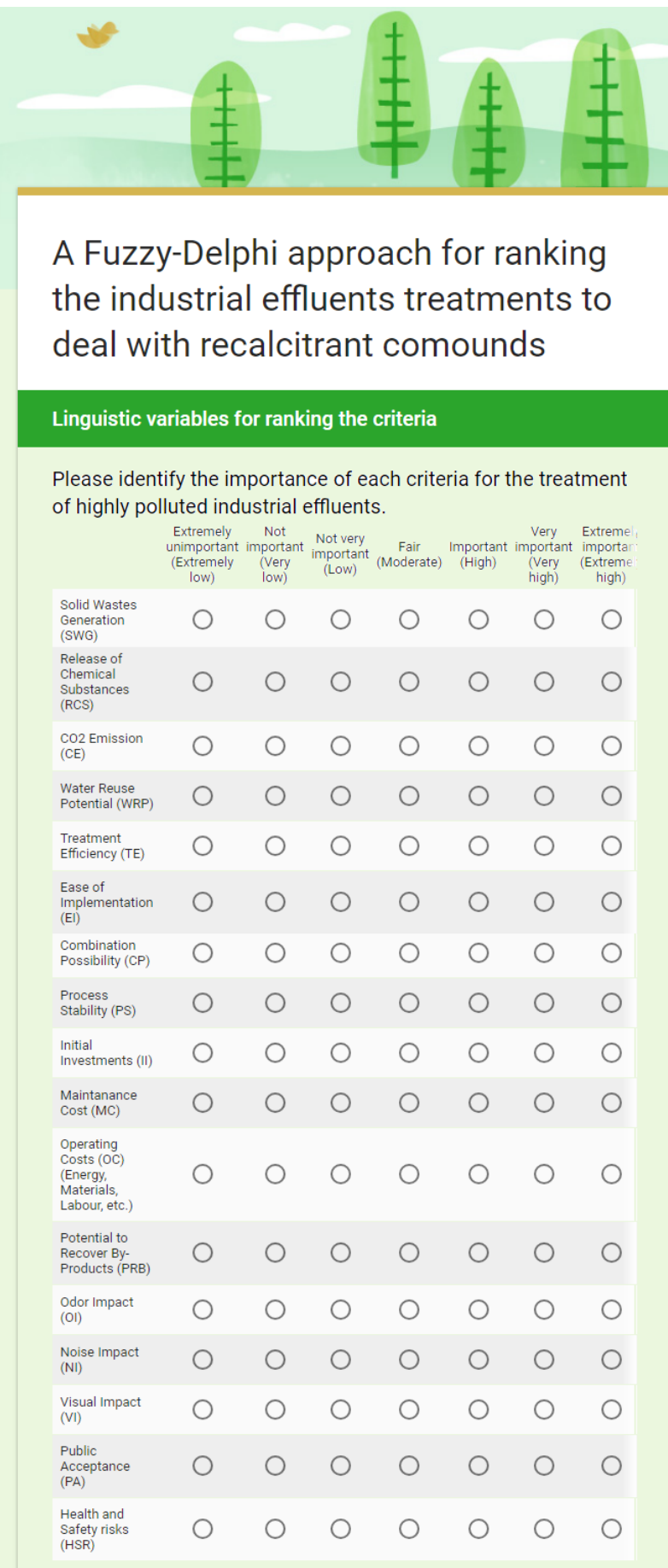




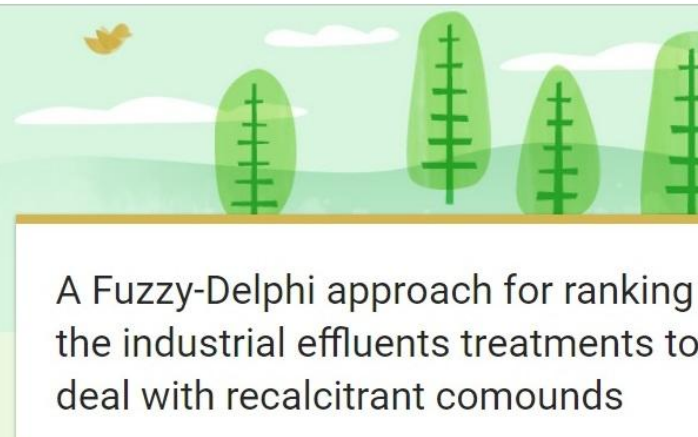

Electrocoagulation

Linguistic variables for rating the method.

Please fill this section if you have previous experience using this method otherwise you can proceed to next section by clicking NEXT button.

Please rate the method in terms of the studied criteria.

veryGood Good Fair Bad very Bad

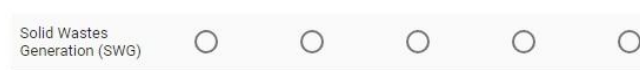

$\begin{array}{llllll}\begin{array}{l}\text { Releaze of } \\ \text { Chemical } \\ \text { Substances (RCS) }\end{array} & 0 & 0 & 0 & 0 & 0\end{array}$

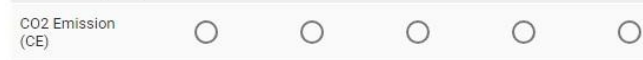

$\begin{array}{llllll}\text { Water Reuse } \\ \text { Potential (WRP) } & 0 & 0 & 0 & 0 & 0\end{array}$

$\begin{array}{lllll}\begin{array}{l}\text { Treatment } \\ \text { Efficiency (TE) }\end{array} & \bigcirc & \bigcirc & \bigcirc & \bigcirc\end{array}$

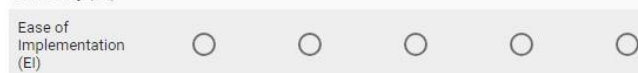

$\begin{array}{llllll}\begin{array}{l}\text { Combination } \\ \text { Possibility (CP) }\end{array} & 0 & 0 & 0 & 0 & 0\end{array}$

$\begin{array}{llllll}\begin{array}{l}\text { Process Stability } \\ \text { (PS) }\end{array} & 0 & 0 & 0 & 0 & 0\end{array}$

\begin{tabular}{|c|}
\hline $\begin{array}{l}\text { Initial } \\
\text { Investments (II) }\end{array}$ \\
\hline
\end{tabular}

$\begin{array}{llllll}\begin{array}{l}\text { Maintanance } \\ \text { cost }(M C)\end{array} & 0 & 0 & 0 & 0 & 0\end{array}$

operating costs

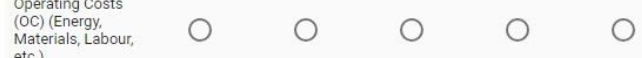

Potential to

$\begin{array}{llll}\text { Recover By- } & 0 & 0 & 0\end{array}$

productsing 0

$\begin{array}{llllll}\operatorname{Odor} \text { Impact (OI) } & \bigcirc & 0 & 0 & 0 & 0\end{array}$

$\begin{array}{lllll}\text { Noise Impact (NI) } & 0 & 0 & 0 & 0\end{array}$

$\begin{array}{llllll}\operatorname{Visual} I m p a c t(V I) & 0 & 0 & 0 & 0 & 0\end{array}$

$\begin{array}{llllll}\begin{array}{l}\text { Public } \\ \text { Acceptance (PA) }\end{array} & 0 & 0 & 0 & 0 & 0\end{array}$

$\begin{array}{llllll}\begin{array}{l}\text { Health and Safety } \\ \text { Considerations } \\ \text { (HSC) }\end{array} & 0 & 0 & 0 & 0 & 0\end{array}$

BACK NEXT 


\title{
1 Sustainability of Treatment Technologies for Industrial
}

\section{Biowastes Effluents}

\author{
Mohammadreza Kamali ${ }^{1,2}$, Maria Elisabete Costa ${ }^{2}$, Tejraj M. Aminabhavi ${ }^{*}{ }^{3}$. Isabel Capela ${ }^{* 1}$ \\ ${ }^{1}$ Department of Environment and Planning, Center for Environmental and Marine Studies, \\ CESAM, University of Aveiro, 3810-193 Aveiro, Portugal \\ 2 Department of Materials and Ceramics Engineering, Aveiro Institute of Materials, CICECO, \\ University of Aveiro, 3810-193 Aveiro, Portugal \\ 3 Pharmaceutical Engineering, Soniya College of Pharmacy, Dharwad, India 580-002
}

\section{Abstract}

Despite the huge efforts to develop efficient technologies for the treatment of recalcitrant biowastes and other emerging pollutants, selecting the most sustainable method among the possible alternatives is still a formidable task. This is mainly because of the integration of technical, economic, environmental, and social criteria in decision-making process. Traditionally, various multi-criteria decision-making approaches have been adopted to integrate innumerable criteria for environmental applications. In this study, we have examined the fuzzy-Delphi approach to evaluate seventeen parameters for integrating technical, economic, environmental and social criteria in order to rank the nine treatment technologies divided in two categories (physico-chemical and biological processes). The results of this study indicated that although efficiency of treatment methods is the most important criterion, but contribution of other sustainability criteria should also be considered because they are of high importance for the selection of sustainable wastewater treatment methods. As per our proposed framework on membrane technologies (among the many other physicochemical methods) and anaerobic sludge blanket technology (among the biological treatment methods) are the most promising approaches for the treatment of highly polluted emerging industrial pollutants. The findings of this study are fully supported by the consensus achieved by a group of fifty experts from nineteen different countries. Opportunities for the improvement of the methods as per data generated are discussed.

Keywords: Sustainability, Fuzzy-Delphi methodology, Biowastes, Physico-chemical methods, Membrane technologies, Biological methods

*Corresponding authors: Isabel Capela (icapela@ua.pt) and Tejraj Aminabhavi (aminabhavit@gmail.com). 


\section{Introduction}

Quality of the final discharged emerging effluents from innumerable industrial activities has been the subject of much debate over the past decades for improving the performance of the methods used either by physico-chemical, biological or a combination of these processes. On the other hand, industries around the world, particularly textile or pulp and paper industries are struggling for their economic profitability [1]. In this situation, stringent environmental regulations have forced the industries, especially those releasing the recalcitrant biowastes compounds, to adopt more efficient treatment methods. Therefore, it is vital to consider both the importance of technical and economic factors while selecting the most appropriate treatment technologies [2]. In addition, long-term sustainability considerations enforce the industries to include environmental and health issues [3] along with the social criteria in decision-making process for selecting the best treatment strategies [4]. Integration of all these aspects while selecting the most appropriate techniques for the treatment of recalcitrant biowastes in industrial effluents is a complex task requiring the need for a multi-criteria analysis framework to identify the most suitable technology.

Due to the inherent advantages of multi-criteria decision making (MCDM) approaches $[5,6]$, such as their strong structure and logic [7], they have been effectively applied to support the decision makers to choose the most appropriate alternative to solve innumerable environmental problems [8]. Delphi, as a MCDM process, is basically conducted through a group of decision-making among the experts with different experiences and knowledge on the same application domain. Two main applications of this process are screening the criteria and forecasting (or evaluating) the performance of a method or technology [9]. Fuzzy-Delphi method (FDM) has thus been developed by the application of traditional Delphi methodology in a fuzzy environment. This technique has been previously employed in sustainable decisions in various fields [10-12]. In this study, we have employed FDM to assess the current opinion of experts in the field of various conventional and emerging technologies for the treatment of recalcitrant biowastes arising from pulp, paper and textile industries.

Selecting the most appropriate technologies to deal with the recalcitrant biowastes and other emerging pollutants in the context of industrial effluents to satisfy the stringent environmental standards while considering various technical, environmental, economic and social aspects is a 
complex task [13]. Multi-criteria decision analysis, as a set of methods allows to identify the most important criteria to rank the available alternatives [14,15]. Even though these methods have been extensively used to rank the relevant criteria to select the most suitable alternatives in various scientific fields, yet only handful of reports are available on the application of MCDMs for selecting suitable wastewater treatment technologies. Arroyo and Molinos-Senante [2] used choosing-by-advantages (CBA) approach to select the most suitable municipal wastewater treatment technology among the widely used methods (constructed wetlands, pond systems, extended aeration, membrane bioreactor [16], rotating biological contactor, trickling filter and sequencing batch reactor) by considering several criteria including treatment efficiency, energy consumption, land area required, sewage sludge production, potential for water reuse, potential to recover by-products, reliability, odor impact, noise impact, visual impact, public acceptance, and complexity of operation. According to the opinions of nineteen participants in this research, odor impact was identified as the most important sustainability criterion and the extended aeration together with the sequencing batch reactor were ranked as the most promising treatment technologies.

A "technique for order of preference by similarity to ideal solution" (TOPSIS) approach was also used in some studies. For instance, Dursun [17] using this technique indicated that sustainability is the most important parameter among the studied factors (i.e., cost, global warming, eutrophication, land requirement, manpower requirement, reliability, sustainability and flexibility). However, the method of sequencing batch reactors (SBRs) is the best approach among of all the investigated technologies (i.e., activated sludge, up-flow anaerobic sludge blanket followed by a facultative aerated lagoon, sequential batch reactor, constructed wetlands). Analytical hierarchy process (AHP) has also been used in recent years in its conventional and advanced forms (e.g., AHP fuzzy approach) in order to select the best wastewater treatment technologies. For instance, Ouyang et. al [18] employed the integrated fuzzy analytical hierarchy process for selecting natural wastewater treatment alternatives. However, the fuzzy-Delphi method for ranking the influencing criteria and to prioritize the most suitable technologies to deal with industrial effluents loaded with recalcitrant biowastes has not been studied hitherto considering both conventional and novel treatment technologies.

\section{Methodology}

\subsection{Problem description and criteria identification}


Some efforts have been made to identify the most appropriate sewage treatment technologies using the multi criteria decision making processes [2]. However, there is a need to understand the current opinion of scientific community on the most important parameters to identify the most suitable technologies to deal with the industrial effluents as per sustainable development goals. In this investigation, seventeen criteria including technical (i.e., treatment efficiency, ease of implementation, combination possibility, process stability, and health and safety risks), environmental (i.e., biowaste waste generation, release of chemical substances, $\mathrm{CO}_{2}$ emission, water reuse potential, and recovery of by-products), economic (i.e., initial investments, maintenance costs, and operating costs), and social (odor impact, noise impact, visual impact, and public acceptance) were considered in order to rank the studied methods for the treatment of industrial effluents. Table 1 presents a list of the studied subcriteria and their descriptions have been provided in the supplementary information.

Table 1. The descriptions of the studied criteria

\begin{tabular}{|c|c|}
\hline Criteria & Description \\
\hline Treatment Efficiency & $\begin{array}{l}\text { Effectiveness of the method for the treatment of recalcitrant biowastes from } \\
\text { industrial effluents, considering all treatment parameters such as operating } \\
\text { conditions, additives, etc.. }\end{array}$ \\
\hline Ease of Implementation & $\begin{array}{l}\text { The level of complexity of the method in terms of required equipment, } \\
\text { expertise needed, etc. }\end{array}$ \\
\hline Combination Possibility & The combination potential of the method with other treatment methods. \\
\hline Process Stability & $\begin{array}{l}\text { Overall reliability of the treatment method against failures and possibility of } \\
\text { re-establishment after probable failures. }\end{array}$ \\
\hline Health and Safety risks & $\begin{array}{l}\text { The health and occupational risks associated with the implementation of the } \\
\text { method. }\end{array}$ \\
\hline Solid Wastes Generation & $\begin{array}{l}\text { Solid wastes (e.g., biowaste generation when the treatment method is } \\
\text { applied. }\end{array}$ \\
\hline Release of Chemical Substances & $\begin{array}{l}\text { The release of additives (mainly chemicals) used for the treatment process } \\
\text { into the effluents content. }\end{array}$ \\
\hline $\mathrm{CO}_{2}$ Emission & $\begin{array}{l}\text { The amount of } \mathrm{CO}_{2} \text { emitted either directly from the treatment process or } \\
\text { indirectly from the treatment facilities, etc. }\end{array}$ \\
\hline Water Reuse Potential & Quality of the treated water. \\
\hline Potential to Recover By-Products & Possibility of the by-products recovery i.e., energy and materials. \\
\hline Initial Investments & $\begin{array}{l}\text { Required initial investments (including land area, equipment, } \\
\text { infrastructures, certificates, etc.). }\end{array}$ \\
\hline
\end{tabular}




\begin{tabular}{|c|c|}
\hline Maintenance Cost & Overall costs required for the maintenance of the facilities. \\
\hline Operating Costs & Overall costs required for energy, materials, labor, etc. \\
\hline Odor Impact & Odor generated from the treatment process. \\
\hline Noise Impact & Noise produced from the process. \\
\hline Visual Impact & Impact of the treatment infrastructures on the local visual properties. \\
\hline Public Acceptance & $\begin{array}{l}\text { Overall public community's perception about the usefulness of the method } \\
\text { for their routine life. }\end{array}$ \\
\hline
\end{tabular}

In this study, expert questionnaires were assisted to collect the current opinion of experts on the performance of the studied treatment methods. A careful protocol was followed to invite experts with excellent academic and/or industrial experience in the concerned area. Linguistic variables and triangular fuzzy numbers (Tables 2 and 3) were utilized in order to determine the importance of evaluation criteria and to rate the studied alternative methods. The questionnaire used to collect the opinion of the experts was provided in the supplementary information.

A fuzzy number is principally defined as a fuzzy set to elaborate a fuzzy interval in the real number, R. Fuzzy numbers are used to explain uncertain information in decision making process [19]. A triangular fuzzy number (as a type of fuzzy numbers) is defined as: $A=\left(\mathrm{a}_{1}, \mathrm{a}_{2}, \mathrm{a}_{3}\right)$. Eq.1 is used to represent the triangular membership functions as [20]:

$$
y=m(x)=\left\{\begin{array}{lr}
0 & x<a_{1} \\
\frac{x-a_{1}}{a_{2}-a_{1}} a_{1} \leq x \leq a_{2} \\
\frac{a_{3}-x}{a_{3}-a_{2}} a_{2} \leq x \leq a_{a} \\
0 & x>a_{a}
\end{array}\right\}
$$

A vertex method was then used to estimate the consensus among the expert group (Eq. 2) by computing the distance, $d(\widetilde{m}, \tilde{n})$, between the aggregated fuzzy numbers $\left(\mathrm{m}_{\mathrm{L}}, \mathrm{m}_{\mathrm{M}}, \mathrm{m}_{\mathrm{U}}\right)$ computed from Eq. 3 and the triangular fuzzy numbers expressed by each expert in the form of linguistic terms.

$$
d(\tilde{m}, \tilde{n})=\sqrt{\frac{1}{a}\left(m_{L}-n_{L}^{i}\right)^{2}+\left(m_{M}-n_{M}^{i}\right)^{2}+\left(m_{U}-n_{U}^{i}\right)^{2}}
$$
The stability of results requires achieving of $75 \%$ of group consensus among the experts [22]. The geometric mean (Eq. 3) [23] was utilized to calculate the fuzzy weights of the criteria and relative 
120 efficiency of the industrial effluents treatment methods, in which L, M and U represent the fuzzy

121 number components.

122

$$
L_{j}=\operatorname{Min}_{i}\left\{L_{i j}\right\}, \quad M_{j}=\frac{1}{n} \sum_{i=1}^{n} M_{i j}, \quad U_{j}=\operatorname{Max}_{i}\left\{U_{i j}\right\}
$$

123 The above equation was used to calculate the relative importance of element number, $j$ allocated by expert number, $i$. In order to perform defuzzification of the final triangular fuzzy numbers, Eq. 4 was utilized.

$$
d f=\frac{1}{4}(L+2 M+U)
$$

Table 2. Linguistic variables and the relevant fuzzy scales for the relative importance of the criteria

\begin{tabular}{lll}
\hline Linguistic variable & $\begin{array}{l}\text { Fuzzy Scale } \\
(\mathrm{L}, \mathrm{M}, \mathrm{U})\end{array}$ & $d f=\frac{1}{4}(L+2 M+U)$ \\
& & \\
\hline Extremely high & $(0.9,1.0,1.0)$ & 0.975 \\
Very high & $(0.7,0.9,1.0)$ & 0.875 \\
High & $(0.5,0.7,0.9)$ & 0.7 \\
Fair & $(0.3,0.5,0.7)$ & 0.5 \\
Low & $(0.1,0.3,0.5)$ & 0.3 \\
Very Low & $(0.0,0.1,0.3)$ & 0.125 \\
Extremely low & $(0.0,0.0,0.1)$ & 0.025 \\
\hline
\end{tabular}

Table 3. Linguistic variables and the relevant fuzzy scales to evaluate the efficiency of the methods

\begin{tabular}{lll}
\hline Linguistic variable & $\begin{array}{l}\text { Fuzzy Scale } \\
(\mathrm{L}, \mathrm{M}, \mathrm{U})\end{array}$ & $d f=\frac{1}{4}(L+2 M+U)$ \\
& & \\
\hline Very good & $(0.75,1,1)$ & 0.937 \\
Good & $(0.5,0.75,1)$ & 0.75 \\
Fair & $(0.25,0.5,0.75)$ & 0.5 \\
Bad & $(0,0.25,0.5)$ & 0.25 \\
Very bad & $(0,0,0.25)$ & 0.0625 \\
\hline
\end{tabular}




$$
A=\left[\begin{array}{c}
A_{1} \\
A_{2} \\
A_{a} \\
\cdot \\
\cdot \\
\cdot \\
A_{m}
\end{array}\right], A=\sum_{i, j=1}^{n} r_{i j} \times w_{j}
$$

Eq. 5

where $r_{i j}$ is the rating of alternative, $i$ with respect to criteria, $j$ and $w_{j}$ is the $j_{\text {th }}$ criterion weight.

\section{Results and discussion}

Due to inherent complexity in selecting the most appropriate industrial effluents treatment method, it is not feasible to rely only on a single aspect such as the technical characteristics. An international panel consisting of fifty high-quality experts from nineteen countries (all over the world with academic and/or industrial experience) contributed in this study to determine the importance of each criterion and to rate the treatment methods according to their previous experiences on the application of different methods for industrial effluent treatment.

\subsection{Prioritization of the criteria}

Figure 1 and Table 4 present fuzzy weights of the studied criteria and sub-criteria after achieving the consensus among experts in the second round of questioning. As per data obtained technical considerations received the highest importance among the studied criteria, with a high relevance allocated to "treatment efficiency" and "health and safety risks". These results could reflect the fact that a technology to be chosen for mitigation of biowastes must be efficient and safe. Despite the fact that innumerable publications have been published on the performance of various industrial effluents treatments [21-24], the health and safety issues attributed to workers using those treatment technologies have not been well investigated. Exposure to biological agents (including bacteria, viruses, fungi (yeasts and mould) and parasites) is considered as one of the most important factors, which affect the safety and health of the workers. The entrance of the spores in human body via many ways such as respiratory tract, damaged skin, eye, etc. may cause severe health problems. In addition, environmental conditions such as humidity and temperature or their combination may provide a favorable environment for the growth of biological agents. Hence, the nature of treatment method applied, and the associated facilities could pose some risks. 
Table 4. Linguistic variables and the relevant fuzzy scale for the relative importance of the criteria

\begin{tabular}{|c|c|c|c|c|c|}
\hline \multirow[t]{2}{*}{ Criteria } & \multirow[t]{2}{*}{ Sub-Criteria } & \multicolumn{3}{|c|}{ Fuzzy values } & \multirow{2}{*}{$\begin{array}{l}\text { De- } \\
\text { fuzzy }\end{array}$} \\
\hline & & $\mathbf{L}$ & $\mathbf{M}$ & $\mathbf{U}$ & \\
\hline \multirow[t]{5}{*}{ Technical } & Treatment Efficiency (TE) & 0.50 & 0.90 & 1.00 & 0.83 \\
\hline & Ease of Implementation (EI) & 0.30 & 0.79 & 1.00 & 0.72 \\
\hline & Combination Possibility (CP) & 0.25 & 0.72 & 1.00 & 0.67 \\
\hline & Process Stability (PS) & 0.30 & 0.83 & 1.00 & 0.74 \\
\hline & Health and Safety Risks (HSR) & 0.50 & 0.90 & 1.00 & 0.83 \\
\hline \multirow[t]{5}{*}{ Environmental } & Solid Wastes (biowaste) Generation (SWG) & 0.10 & 0.79 & 1.00 & 0.67 \\
\hline & Release of Chemical Substances (RCS) & 0.00 & 0.90 & 1.00 & 0.70 \\
\hline & $\mathrm{CO}_{2}$ Emission (CE) & 0.00 & 0.74 & 1.00 & 0.62 \\
\hline & Water Reuse Potential (WRP) & 0.10 & 0.79 & 1.00 & 0.67 \\
\hline & Potential to Recover By-Products (PRB) & 0.25 & 0.75 & 1.00 & 0.69 \\
\hline \multirow[t]{3}{*}{ Economic } & Initial Investments (II) & 0.10 & 0.77 & 1.00 & 0.66 \\
\hline & Maintenance Cost (MC) & 0.10 & 0.80 & 1.00 & 0.67 \\
\hline & Operating Costs (OC) & 0.30 & 0.84 & 1.00 & 0.75 \\
\hline \multirow[t]{4}{*}{ Social } & Odor Impact (OI) & 0.10 & 0.74 & 1.00 & 0.64 \\
\hline & Noise Impact (NI) & 0.10 & 0.70 & 1.00 & 0.63 \\
\hline & Visual Impact (VI) & 0.00 & 0.64 & 1.00 & 0.57 \\
\hline & Public Acceptance (PA) & 0.00 & 0.75 & 1.00 & 0.63 \\
\hline
\end{tabular}

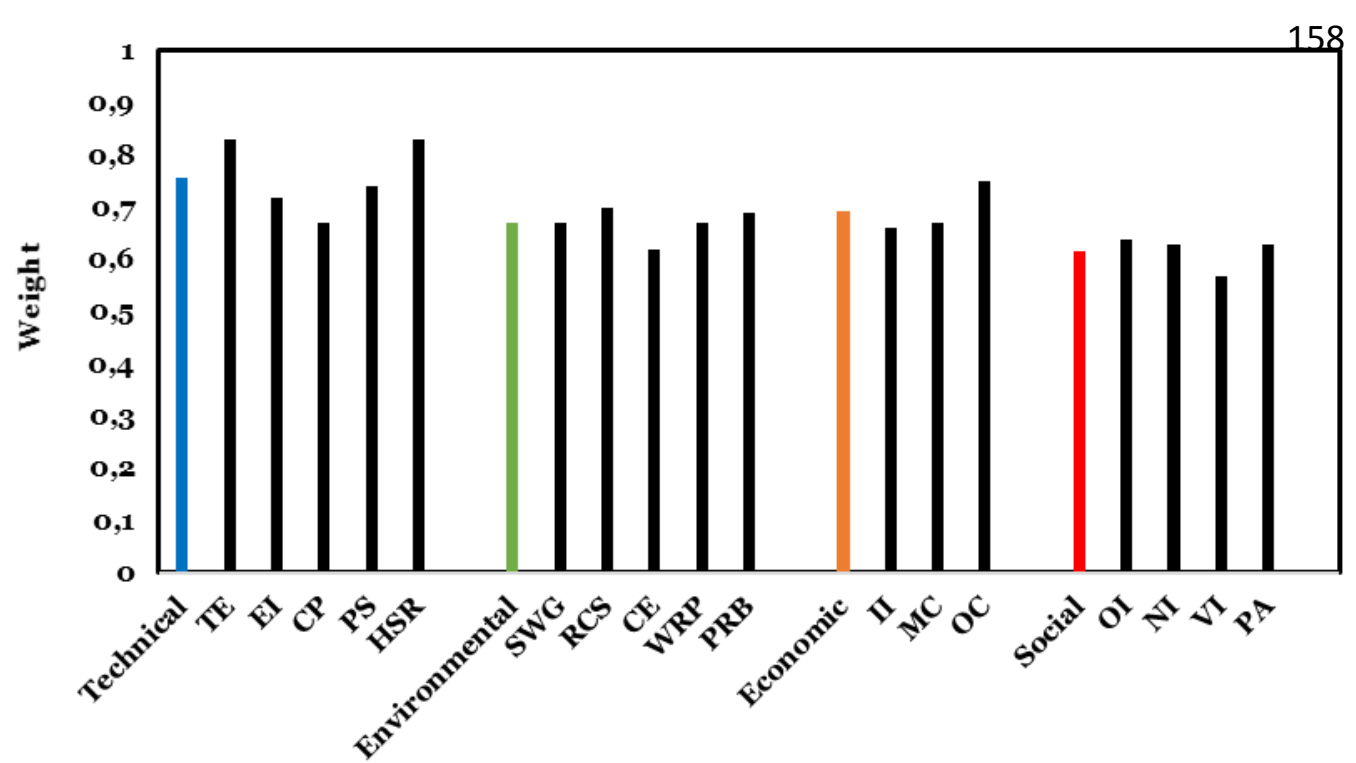

Criteria and respective sub-criteria 
Fig. 1. Calculated weights of the criteria and sub-criteria, measured as the average of the respective sub-criteria. The results indicate that technical criteria are most important for selecting the most sustainable industrial effluents treatment technologies. Economic criteria are in the second position of importance followed by environmental and social parameters. In addition, treatment efficiency, health and safety risks are the most important parameters among the influencing criteria. The abbreviations are described in Table 4.

Economic criteria, i.e., initial investments, maintenance and operation costs have received the next importance among the studied criteria. For many industries, which need to comply with stringent environmental regulations, there is currently a declining and competitive market for their product [1]. This reflects the importance of economic considerations for the treatment of industrial effluents such as biowastes. However, the potential of water reuse as well as other environmental factors are of relatively high importance as also expressed by the participating experts. There are some factors determining the quality of treated water for reuse such as efficiency of the applied treatment methods and additives, which are normally added to the wastewater sources during the treatment process and extraction of by-products from the effluents.

The emission of $\mathrm{CO}_{2}$ is an important environmental issue. The $\mathrm{CO}_{2}$ emission (CE) has received the least importance among the studied environmental criteria. However, considering the values presented in Table 4, the weight of this criterion (o.62) is above the fair (see Table 2) and this should be considered in the decision-making process. In this regard, those methods with the ability to control emission of greenhouse gases and those in which the treatment process is conducted via mechanisms leading to the production of end products other than $\mathrm{CO}_{2}$ (e.g., methane), can be more environmentally-friendly, and are better accepted.

The values of the most environmental sub-criteria are close to the economic sub-criteria, while the average weights of social criteria received the least importance among the main categories (table 4 and figure 1). This reflects the higher importance of both environmental and economic criteria in the experts' points of view as compared to social criteria. Furthermore, the fact that the importance of both environmental and economic criteria is similar indicates that nowadays pollution issues are as important as economic aspects related mainly to initial investment, operating and maintenance costs. Regarding the social criteria, their weights evidence the need to be considered when selecting the most appropriate treatment alternatives. 
The main improvement opportunities of some of the most widely used treatment alternatives for industrial effluents will be discussed here.

192

193

194

\subsection{Ranking the treatment technologies}

Various physico-chemical treatment methods have so far been applied for the treatment of industrial effluents such as biowastes. Coagulation and precipitation, membrane technologies, adsorption and oxidation processes are among the most effective and widely accepted techniques. Biological treatments, used as a single treatment or in combination with other physico-chemical methods have also been widely explored for the treatment of industrial effluents [13]. Although they have a number of advantages, including being eco-friendly and cost-effective, they exhibit lack of efficiency for the removal of recalcitrant biowastes due to their low biodegradability in highly polluted industrial effluents. However, scientific efforts are in progress to promote their efficiency for such applications. Pond systems, aerated lagoons, activated sludge and anaerobic sludge blanket technologies are the main biological treatments that have been applied so far for the treatment of industrial effluents around the world. The results of fuzzy-Delphi method for the investigated physicochemical and biological treatment methods are summarized in Tables 5 and 6, respectively. As summarized in Table 5, the most sustainable physico-chemical method for the treatment of industrial effluents is membrane-based technologies followed by adsorption, oxidation with nanomaterials and Fenton process. Membrane-based technologies have gained the highest scores in technical criteria (2.79) as well as in environmental criteria (2.27), while those of adsorption-based technologies are the most efficient in terms of economic and social criteria. However, considering all criteria, membranebased technologies have been identified as the most sustainable technology to deal with industrial effluents. Therefore, it can be highly correlated with the advances in the fabrication of novel membrane structures, mainly inorganic membranes (ceramic) and those decorated with engineered nanomaterials to increase the treatment efficiency and to decrease the fouling properties of the membranes [28]. 


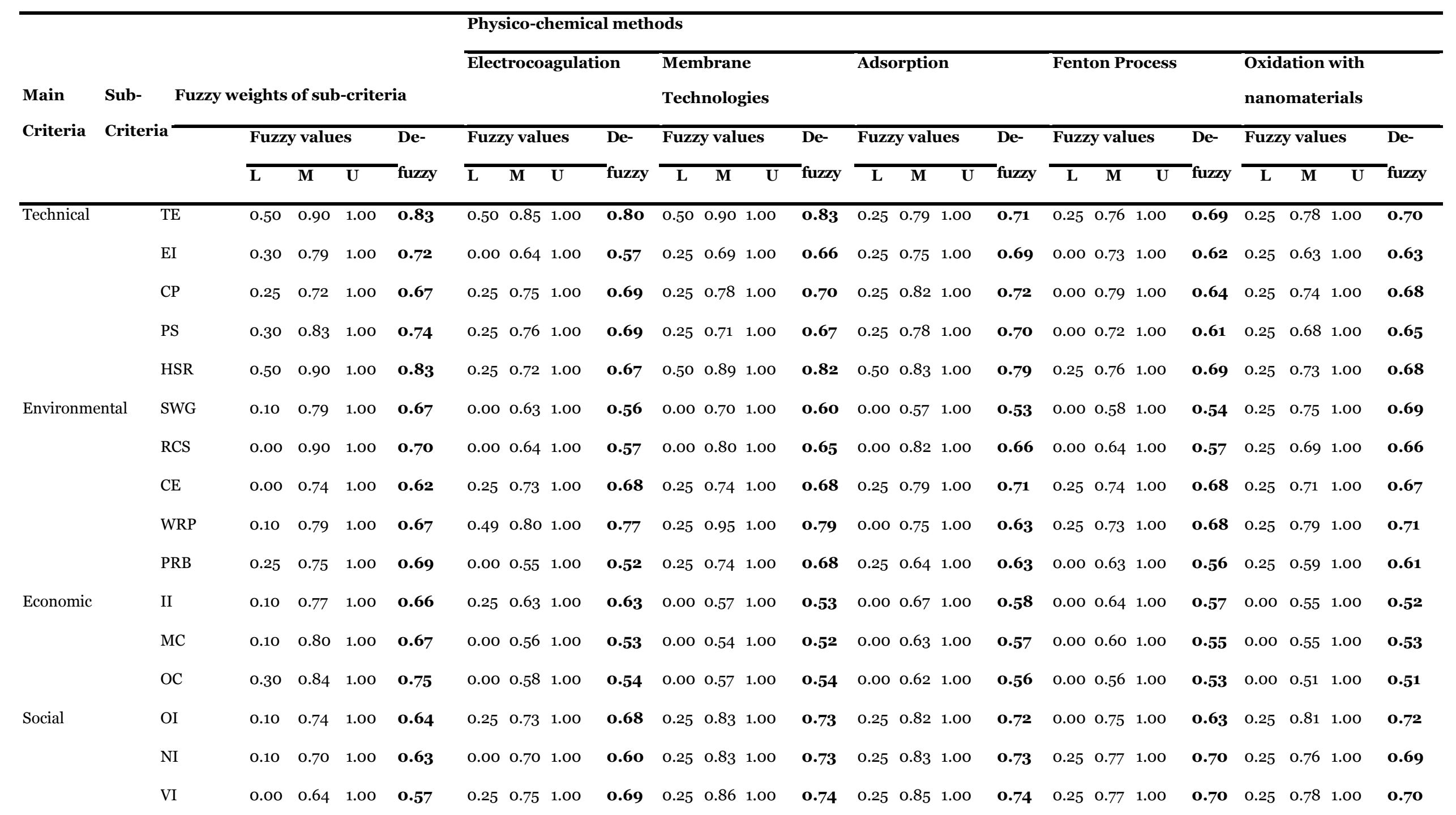




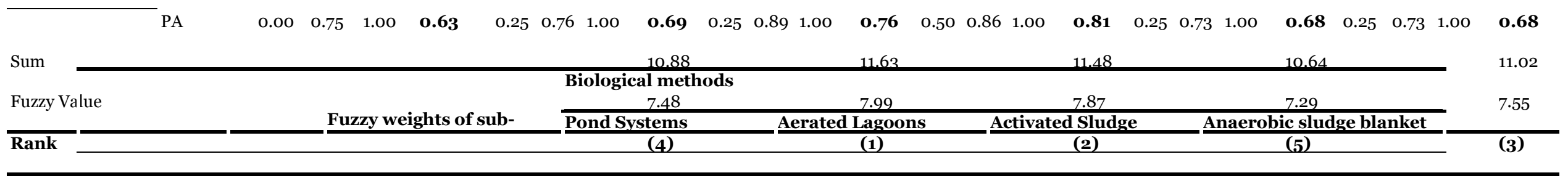

Table 5. The average fuzzy values and de-fuzzy numbers allocated by the experts to the studied physico-chemical methods.

Table 6. The average fuzzy values and de-fuzzy numbers allocated by the experts to the studied biological methods 


\begin{tabular}{|c|c|c|c|c|c|c|c|c|c|c|c|c|c|c|c|c|c|c|c|c|c|}
\hline \multirow[t]{3}{*}{ Main Criteria } & \multirow{3}{*}{$\begin{array}{l}\text { Sub- } \\
\text { Criteria }\end{array}$} & \multicolumn{16}{|c|}{ criteria } & \multicolumn{4}{|c|}{ technologies } \\
\hline & & \multicolumn{3}{|c|}{$\overline{\text { Fuzzy values }}$} & \multicolumn{4}{|c|}{ De-fuzzy Fuzzy values } & \multirow{2}{*}{$\begin{array}{l}\text { De- } \\
\text { fuzzy }\end{array}$} & \multicolumn{3}{|c|}{ Fuzzy values } & \multirow{2}{*}{$\begin{array}{l}\text { De- } \\
\text { fuzzy }\end{array}$} & \multicolumn{3}{|c|}{ Fuzzy values } & \multirow{2}{*}{$\begin{array}{c}\text { De- } \\
- \text { fuzzy }\end{array}$} & \multicolumn{3}{|c|}{ Fuzzy values } & \multirow[t]{2}{*}{$\overline{\text { De-fuzzy }}$} \\
\hline & & $\overline{\mathbf{L}}$ & $\overline{\mathbf{M}}$ & $\overline{\mathbf{U}}$ & & $\overline{\mathbf{L}}$ & $\overline{\mathbf{M}}$ & $\overline{\mathbf{U}}$ & & $\overline{\mathbf{L}}$ & $\overline{\mathbf{M}}$ & $\overline{\mathbf{U}}$ & & $\overline{\mathbf{L}}$ & $\overline{\mathbf{M}}$ & $\overline{\mathbf{U}}$ & & $\overline{\mathbf{L}}$ & $\overline{\mathbf{M}}$ & $\overline{\mathbf{U}}$ & \\
\hline \multirow[t]{5}{*}{ Technical } & $\mathrm{TE}$ & 0.50 & 0.90 & 1.00 & 0.83 & 0.00 & 0.58 & 1.00 & 0.54 & 0.25 & 0.68 & 1.00 & 0.65 & 0.25 & 0.76 & 1.00 & 0.69 & 0.25 & 0.63 & 1.00 & 0.63 \\
\hline & EI & 0.30 & 0.79 & 1.00 & 0.72 & 0.25 & 0.75 & 1.00 & 0.69 & 0.25 & 0.72 & 1.00 & 0.67 & 0.25 & 0.73 & 1.00 & 0.68 & 0.00 & 0.60 & 1.00 & 0.55 \\
\hline & $\mathrm{CP}$ & 0.25 & 0.72 & 1.00 & 0.67 & 0.25 & 0.63 & 1.00 & 0.63 & 0.25 & 0.66 & 1.00 & 0.64 & 0.25 & 0.73 & 1.00 & 0.68 & 0.00 & 0.65 & 1.00 & 0.58 \\
\hline & PS & 0.30 & 0.83 & 1.00 & 0.74 & 0.00 & 0.64 & 1.00 & $\mathbf{0 . 5 7}$ & 0.25 & 0.70 & 1.00 & 0.66 & 0.25 & 0.68 & 1.00 & 0.65 & 0.00 & 0.60 & 1.00 & 0.55 \\
\hline & HSR & 0.50 & 0.90 & 1.00 & $\mathbf{0 . 8 3}$ & 0.00 & 0.65 & 1.00 & 0.58 & 0.00 & 0.63 & 1.00 & 0.57 & 0.00 & 0.64 & 1.00 & $\mathbf{0 . 5 7}$ & 0.25 & 0.60 & 1.00 & 0.61 \\
\hline \multirow[t]{5}{*}{ Environmental } & SWG & 0.10 & 0.79 & 1.00 & 0.67 & 0.00 & 0.53 & 1.00 & 0.52 & 0.00 & 0.55 & 1.00 & 0.52 & 0.00 & 0.51 & 1.00 & 0.51 & 0.00 & 0.63 & 1.00 & 0.57 \\
\hline & RCS & 0.00 & 0.90 & 1.00 & 0.70 & 0.00 & 0.59 & 1.00 & 0.55 & 0.25 & 0.58 & 1.00 & 0.60 & 0.00 & 0.65 & 1.00 & 0.58 & 0.00 & 0.63 & 1.00 & $\mathbf{0 . 5 7}$ \\
\hline & $\mathrm{CE}$ & 0.00 & 0.74 & 1.00 & 0.62 & 0.00 & 0.47 & 1.00 & 0.48 & 0.00 & 0.45 & 1.00 & 0.47 & 0.00 & 0.54 & 1.00 & 0.52 & 0.00 & 0.58 & 1.00 & 0.54 \\
\hline & WRP & 0.10 & 0.79 & 1.00 & 0.67 & 0.00 & 0.52 & 1.00 & 0.51 & 0.00 & 0.59 & 1.00 & 0.54 & 0.00 & 0.68 & 1.00 & 0.59 & 0.00 & 0.55 & 1.00 & 0.53 \\
\hline & PRB & 0.25 & 0.75 & 1.00 & 0.69 & 0.00 & 0.47 & 1.00 & 0.48 & 0.00 & 0.44 & 1.00 & 0.47 & 0.00 & 0.59 & 1.00 & 0.54 & 0.00 & 0.79 & 1.00 & 0.64 \\
\hline \multirow[t]{3}{*}{ Economic } & II & 0.10 & 0.77 & 1.00 & 0.66 & 0.00 & 0.67 & 1.00 & 0.58 & 0.00 & 0.68 & 1.00 & 0.59 & 0.00 & 0.64 & 1.00 & $\mathbf{0 . 5 7}$ & 0.00 & 0.57 & 1.00 & 0.54 \\
\hline & MC & 0.10 & 0.80 & 1.00 & 0.67 & 0.00 & 0.72 & 1.00 & 0.61 & 0.00 & 0.59 & 1.00 & 0.55 & 0.00 & 0.62 & 1.00 & 0.56 & 0.00 & 0.68 & 1.00 & 0.59 \\
\hline & $\mathrm{OC}$ & 0.30 & 0.84 & 1.00 & 0.75 & 0.25 & 0.79 & 1.00 & 0.71 & 0.00 & 0.58 & 1.00 & 0.54 & 0.00 & 0.58 & 1.00 & 0.54 & 0.25 & 0.74 & 1.00 & 0.68 \\
\hline \multirow[t]{4}{*}{ Social } & OI & 0.10 & 0.74 & 1.00 & 0.64 & 0.00 & 0.37 & 1.00 & 0.43 & 0.00 & 0.38 & 1.00 & 0.44 & 0.00 & 0.44 & 1.00 & 0.47 & 0.00 & 0.48 & 1.00 & 0.49 \\
\hline & NI & 0.10 & 0.70 & 1.00 & 0.63 & 0.00 & 0.61 & 1.00 & 0.56 & 0.00 & 0.46 & 1.00 & 0.48 & 0.00 & 0.54 & 1.00 & 0.52 & 0.25 & 0.69 & 1.00 & 0.66 \\
\hline & VI & 0.00 & 0.64 & 1.00 & 0.57 & 0.00 & 0.44 & 1.00 & 0.47 & 0.00 & 0.49 & 1.00 & 0.49 & 0.00 & 0.52 & 1.00 & 0.51 & 0.00 & 0.65 & 1.00 & $\mathbf{0 . 5 7}$ \\
\hline & PA & 0.00 & 0.75 & 1.00 & 0.63 & 0.00 & 0.52 & 1.00 & 0.51 & 0.00 & 0.61 & 1.00 & 0.55 & 0.00 & 0.65 & 1.00 & $\mathbf{0 . 5 7}$ & 0.25 & 0.63 & 1.00 & 0.63 \\
\hline Sum & & & & & & & & & 9.42 & & & & 9.43 & & & & 9.75 & & & & 9.93 \\
\hline
\end{tabular}


Fuzzy Value

6.50

6.54 
Novel technologies such as advanced oxidation with nanomaterials are also moderately sustainable due to some existing barriers, which needs to be overcome[29]. Due to high potential of such technologies to satisfy the future needs for clean water resources, more efforts are required, especially in terms of economic (i.e., operating cost) and social considerations (i.e., social acceptance) to push these technologies for commercialization. In this sense, development of cheaper nanomaterials with the ability to be recovered and re-used and with also low toxic effects [30], are highly welcome as a strategic key for the development of advanced oxidation technologies with nanomaterials. Fenton-based technologies have also suffered from the weaknesses such as the release of relatively high amounts of chemicals. Development of facilities to recover chemicals before discarding would push up this technology by reducing both subsequent environmental risks and operating costs.

Among the biological treatment methods (Table 6) activated sludge has been identified as the most promising technology in terms of technical criteria (score: 2.47). However, considering all criteria (i.e. technical, environmental, economic and social), anaerobic sludge blanket was identified as the most sustainable technology (overall score: 6.82). This technology has gained the highest score in environmental criteria (1.90) compared to other studied biological technologies. It means that anaerobic sludge blanket is a green biological technique to deal with industrial effluents. It has also achieved the highest score (1.45) in social criteria, which would indicate that this technology may be selected as a socially acceptable technique. In addition, while pond systems are the most economic biological technique (score: 1.32), it cannot be selected as the most sustainable technology for the treatment of industrial effluents. It can clearly reflect the fact that considering all the sustainability criteria can highly affect the decision-making process to identify the most sustainable technology to deal with biowaste mitigation.

Furthermore, biological treatment methods are not generally sufficient enough to deal with recalcitrant biowastes such as adsorbable organic halides (AOXs). The effluents with high loads of such environmental contaminants may decrease the performance of such systems and even causing their failure. In order to overcome this issue, a combination of biological methods, as post-treatment, with oxidation with nanomaterials may be an alternative approach. However, published reports are quite rare on such combinations, which need more efforts to make the 
treatment methods more sustainable to deal with biowaste containing recalcitrant and toxic compounds.

\subsection{Development opportunities}

According to the results achieved, the main potentials for improvement of each method are briefly presented and discussed in the following sections.

\subsubsection{Physico-chemical methods}

Currently, membrane technologies are still the leading wastewater treatment methods to overcome global water pollution challenges[28]. Besides the high treatment efficiency of these technologies [31], they can contribute to the recovery of organics [32] and inorganic compounds $[30,31]$ present in the effluents. However, as it can be seen in Table 5, the operating cost (0.54) is still the main obstacle of the wider application of this method. Recent studies have mainly focused on the development of polymeric and inorganic (ceramic) membranes. Goh and Ismail [28] reviewed the latest progress in the fabrication of a new class of inorganic nanostructures, i.e. ceramic membranes (such as metal oxide membranes, zeolite membranes, metal organic framework membranes), and carbon-based membranes (such as carbon nanotubes membranes, and graphene membranes) as the promising materials for industrial treatment purposes. They concluded that the operating cost is still the main barrier for rapid commercialization of new branches of membrane technologies. In this regard, reduction of production costs through the development and use of cheap raw materials and development of efficient and cost-effective fabrication methods for membranes can be considered to be interesting to study. There are some evidences for such approaches in the literature. For instance, Scheibler et al. [35] developed a ultrafiltration process composed of a low-cost multilayer $\gamma-\mathrm{Al}_{2} \mathrm{O}_{3}$ ceramic membrane for the pre-treatment of oily wastewater. Zhu et al. [36] prepared a titanium dioxide membrane supported onto mullite hollow fiber synthesized from industrial solid waste coal fly ash as a low-cost alternative for the treatment of oily effluent.

In addition to the operating costs associated with the membrane preparation, fouling is considered another bottleneck on the application of these technologies. Bagheri and Ahmad [37] reviewed fouling mitigation technologies to conclude that application of nanomaterials, electrical and mechanical methods, ultrasonic irradiation, and their combination with biological 
treatments (Fig. 2) can be considered as effective strategies to deal with this problem. However, none of these methods has yet been used in full-scale technologies to prove their efficiency with real industrial effluents. Table 7 represents the main advantages and disadvantages of various physico-chemical treatment methods for the treatment of recalcitrant biowastes and mitigation of emerging pollutants from the industrial effluents.

279 Table 7. Some literature reports on the advantages and disadvantages of the studied physico-chemical methods

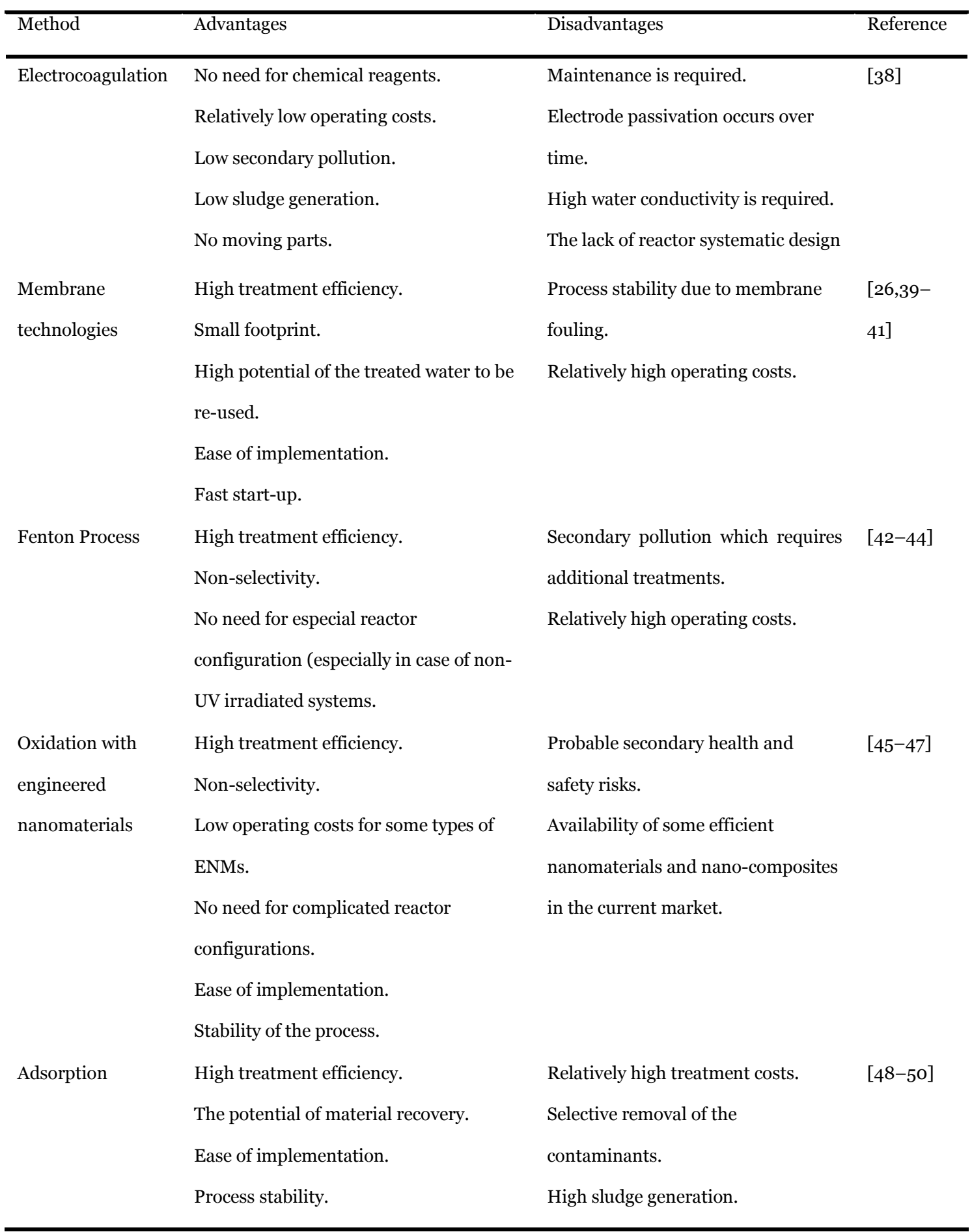




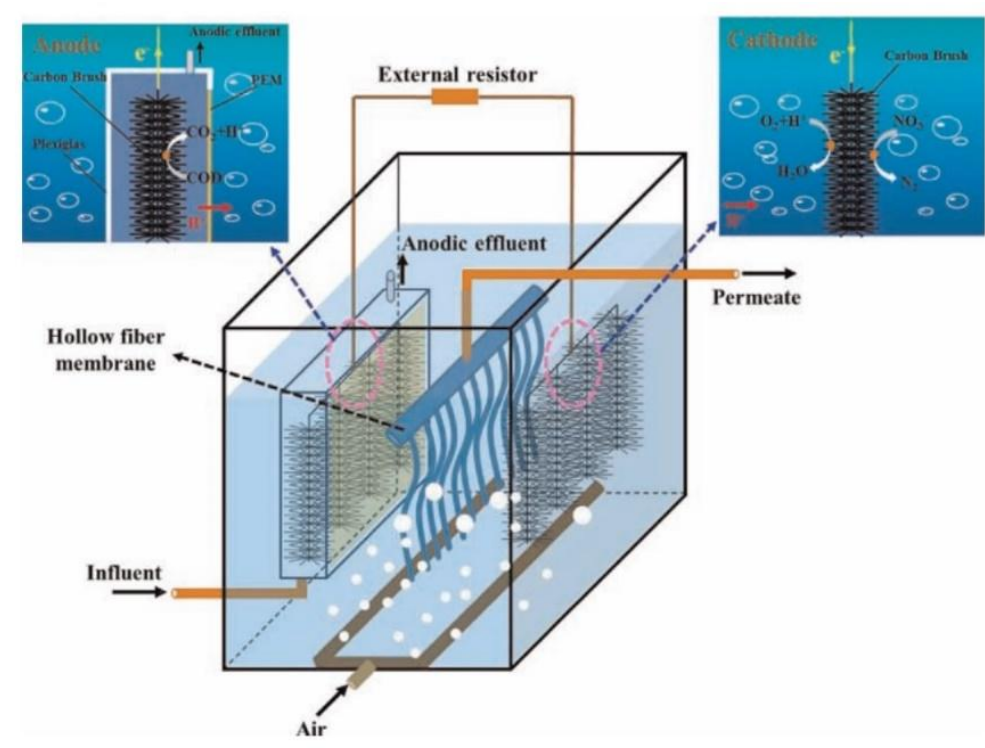

281

282

283

284

285

286

287

288

289

290

291

292

293

294

295

296

297

Fig. 2. A schematic of an in-situ integration of microbial fuel cell with hollow-fiber membrane bioreactor in order for treatment of wastewaters. Such a combinaion is also very effective for the mitigation of the membrane fouling due to thebiological decomposition of organic compounds responsible for the membrane fouling, reprinted with permission from Tian et al., 2015 [51].

Adsorption has also been widely studied as one of the most efficient and effective treatment technologies [52], easy to operate and well-suited for materials and nutrients recycling [53]. However, some environmental drawbacks related to solid waste generation (see Table 5) can hinder the promotion of adsorption to deal with the industrial effluents. Activated carbon is a widely used material for this process. However, such a conventional material is very expensive, especially for high quality products [54]. Hence, finding low-cost alternatives has been the subject of a number of recent studies. For instance, Castro et al. [55] indicated that application of cork granules is a cheap material for the treatment of textile effluents. Especially, the operating costs will significantly increase when a highly polluted effluent is subjected to treatment. For instance, Wang et al. [56] used combination of adsorption (wooden activated carbon) at a dosage of $10 \mathrm{~g} / \mathrm{L}$, and $1500 \mathrm{mg} / \mathrm{L}$ of polymeric magnesium ferric sulfate for subsequent coagulation process. This combination increased significantly the efficiency of the system to treat highly polluted effluents. This possibility derived from activated carbon (AC) can be economically beneficial compared to conventional AC processes.

Agriculture wastes have also been studied as the economic alternative material to be used in the treatment of industrial effluents. As an example, acid-washed coconut shell-based activated carbon (CSAC) has been used successfully for the treatment of palm oil mill effluents [56]. Bello et al. [54] used banana pseudo-stem, a plant waste of banana, as a cheap source of cellulose for the removal of 
dyes from industrial effluents. In recent years, several nanostructured materials have also been developed for the adsorption of complex organic pollutants in the context of effluents treatment. For a nanomaterial to be used for adsorption applications, specific surface area is considered to be the determinant factor [47]. For instance, Heydartaemeh [52] prepared a nanocomposite $\left(\mathrm{Ni}_{\mathrm{X}} \mathrm{Zn} \mathrm{n}_{\mathrm{X}}-\mathrm{X}\right.$ $\mathrm{Fe}_{2} \mathrm{O}_{4}$ ) with a specific surface area of $120 \mathrm{~m}^{2} / \mathrm{g}$ having a maximum of $90 \%$ of green malachite adsorption after $120 \mathrm{~min}$. Being low-cost, this feature is a main advantage for these materials in terms of their application for industrial treatment purposes.

Advanced oxidation processes have been identified in recent years as efficient methods (see Table 5) to deal with recalcitrant biowastes. The generation of powerful hydroxyl radicals in the medium are the basis of advanced oxidation of recalcitrant pollutants. Fenton reactions and oxidation with engineered nanomaterials are the main processes based on the generation of hydroxyl radicals. The reaction between iron salts and hydrogen peroxide is the basis of Fenton process [57] and short reaction time is the main advantage of this process [58]. Photo-Fenton process using ultraviolet irradiation (UVI) offers higher removal efficiency compared to conventional Fenton process, although it may bring some safety issues and higher operating costs [59]. The main drawback of Fenton processes, however, is the generation of secondary pollutants by releasing ferric ion to the effluents [6o]. As a result, additional treatment is required, for instance, by precipitation of the ferric ions through the $\mathrm{pH}$ increase of the effluents [61]. This additional treatment may result in generating ironcontaining sludge, whose treatment would be expensive and needs a high amount of chemicals $[62,63]$.

In order to overcome these drawbacks, heterogeneous Fenton reactions based on the application of iron oxide nanomaterials or other types of inorganic nanomaterials such as titanium dioxide, copper-based nanomaterials, etc., have gained a huge attention in recent years [27, 62, 63]. However, the reaction kinetics of these processes are slower than those with Fenton process [6o]. The properties of nanomaterials such as high specific surface area and agglomeration state may also play a critical role in nano-catalytic processes. The main mechanisms involved in the removal or degradation of the pollutants using nanomaterials consist on the chemisorption of the pollutants on the surface of the materials, transformation of hydrogen peroxide to hydroxyl radicals on the surface of the materials followed by the decomposition of the adsorbed pollutants [66]. UVI can also assist in the generation and decomposition of hydrogen peroxide to hydroxyl radicals onto the surface of the nanomaterials.

As can be seen in Table 5, the economic considerations (i.e., operating costs) are still the main fields for improvements with the application of advanced oxidation processes. In recent years, a trend 
can be seen in the literature for the synthesis of low-cost catalytic materials with the ability to work under visible light irradiation, for instance by introducing nitrogen into the structure of titanium dioxide nanomaterials, as one of the most widely applied nanomaterials for wastewater treatment [67]. In spite of the inherent advantages on the application of engineered nanomaterials for the treatment of industrial effluents such as biowastes, the subsequent health problems arising from the possible toxic effects of nanomaterials are now under much debate [66-69]. Although some in vitro and in vivo studies have shown that some types of the nanomaterials such copper oxide nanoparticles [47] can cause toxic effects on terrestrial and aquatic organisms, the probable health problems associated with the use of nanomaterials have not yet been widely investigated and understood.

Electrocoagulation has also been successfully applied in recent years for the treatment of a variety of pollutants in order to reduce parameters such as chemical oxygen demand (COD), color, recalcitrant compounds, etc., from the industrial effluents. The basis of coagulation process is to introduce metal salts to the stream in order to generate larger flocs from small particles. In the electrocoagulation process, metal cations are dissolved from the anode, resulting in simultaneous formation of hydroxide ions and hydrogen in the form of gas at the cathode $\left(\mathrm{Eq}_{\mathrm{s} .}\right.$ 5, 6).

$$
\mathrm{M}^{\mathrm{O}} \rightarrow \mathrm{M}^{\mathrm{n}+}+\mathrm{n} e^{-}
$$

Eq. 5

$$
\mathrm{nH}_{2} \mathrm{O}(l)+\mathrm{n}^{-} \rightarrow \mathrm{nOH}^{-}+\frac{n}{2} \mathrm{H}_{2}(\mathrm{~g}) \quad \text { Eq. } 6
$$

While in the conventional coagulation methods, coagulants such as aluminium chloride [72] are used, in the electrocoagulation process there is no need for any coagulant to be added to the effluents. Hence, the main advantage of this process is to mitigate the release of chemical substances into the treated effluent [73]. This method has been considered as an efficient solution for a sustainable industrial wastewater treatment. However, several parameters such as current density, operating $\mathrm{pH}$, electrolyte type and passivation, reactor design, etc., can determine its efficiency for the treatment of highly polluted industrial effluents. These factors can determine electrical energy requirement and operating costs including the costs of electrodes, electrode replacement, chemicals used for $\mathrm{pH}$ and electric conductivity adjustment, etc. Recently, some measures have been applied in order to reduce the operating costs of this process such as the use of Fe electrodes instead of other metals such as aluminium [13]. 
For electrocoagulation process to be more economic there is a need to increase the efficiency of the energy used in the system. For instance, Cheng-ChunHe et al. [74] indicated that chloride addition and ultrasonic processing can increase the energy efficiency of the system by removing the passivation layer on the electrodes used for electrocoagulation. Reducing the sludge generation in coagulation processes is another potential for improvement in the application of this technology. Considering that the cost of sludge disposal is remarkable [75], the related costs should be included in the design of the treatment facilities using electrocoagulation techniques. Hence, there is a greater need for more studies on the reduction of sludge volume in this technology.

\subsubsection{Biological treatments}

Stabilization ponds, as an artificial ecosystem, consist on the co-existence of different biological communities such as bacteria, protozoa, alga, fungi, and crustacean larvae. Generally, stabilization ponds are partially aerobic and partially anaerobic in a basin with a depth of about 1 to 2 meters. These systems have been used for the treatment of a variety of industrial effluents, especially in under developed countries. For instance, in Malaysia, stabilization ponds are the most widely used methods for the treatment of palm oil production mill effluents[76].In fact, they are good options when large land areas are available for such treatment installations. Although they have shown to some extent as the acceptable treatment efficiency, there are still some drawbacks in the application of these systems.

Large amounts of greenhouse gases such as carbon dioxide and methane are released from the open ponds into the atmosphere. In addition to the effects of these systems on the global warming, the recovery of energy in the form of methane gas is highly limited from such systems [75,76].Sia et al. [76] stated that by 2020 ponding systems in Malaysia will release 7.2 million tonnes of $\mathrm{CO}_{2}$ into the atmosphere. Although some measures such as application of photosynthetic bacteria to recover $\mathrm{CO}_{2}$ in the form of bacterial cell [79] have been adopted for capturing carbon dioxide, this problem is still considered as the major deficiency of these systems. The odor impact is another issue in pond systems though some studies are available in the literature to mitigate this problem. Truppel et al. [80] achieved a reduction of odor of a treatment plant located near a populated area by recirculation of the effluent followed by aeration of the pond. The combination of pond systems with other treatment facilities may also be considered as an effective solution to deal with this problem and also to increase the quality 
of the treated effluents. For instance, Liu et al. [81] used a combination of a pond system and a wetland to increase the overall efficiency of the system for the treatment of refractory organic pollutants in petrochemical industrial wastewater.

Aerated lagoons have also been extensively used for the treatment of industrial effluents such as kraft mill effluents [80, 81].These systems present acceptable performance for the removal of biological oxygen demand (BOD) from industrial effluents[13]. However, some studies have shown that their performance for the removal of color from the effluents is considered as one of the drawbacks of these systems. Also, energy input and daily maintenance costs are the main challenges of using these systems, which require the development of efficient aeration and mixing technologies with acceptable energy efficiency. However, by increasing the efficiency of the systems in order to promote biodegradation, the sludge accumulation will occur as one of the main disadvantages of such systems. These may lead to the increase of suspended biomass, which needs a final treatment such as filtration with an increase of further treatment cost.

Over the past decade, many industries have started upgrading their aerated lagoons to activated sludge systems due to the advantages of such systems [83]. Xavier et al. [83] compared the aerated lagoon with activated sludge processes to conclude that activated sludge system might present better efficiency for the treatment of kraft pulp and paper mill effluents, except for phenolic compounds.

In addition to the activated sludge processes, anaerobic sludge blanket processes are the most widely used anaerobic treatment methods in many industries[82, 83]. From Table 5, it is evident that although the treatment efficiency of activated sludge process has received a higher value (0.69) compared to that of the anaerobic sludge blanket technology (0.63), the latter technology was identified as the more sustainable one to deal with industrial effluents. It demonstrates the importance of other sustainability criteria to achieve a final decision to be adopted for an industrial wastewater treatment method. However, in spite of the acceptable performance of both the mentioned biological systems, these methods are now struggling with some certain disadvantages such as relatively high sludge production, especially in the case of activated sludge.

Although the degradation mechanism of the recalcitrant biowaste pollutants in anaerobic digestion processes leads to the formation of biogas (mainly methane), and thereby reducing the 
emission of greenhouse gases, they are sensitive to some inhibitory elements such as sulfide and toxic substances [86]. Considering that methane is an important greenhouse gas with potential 34-times higher than carbon dioxide, the production of this gas can significantly contribute to the emission of greenhouse gases. However, by using the produced gas as a source of energy, the anaerobic process can be more cost-effective when compared to activated sludge processes. However, the need for the supply of alkalinity may increase the energy consumption and greenhouse gases (GHGs) generation in anaerobic treatment process. The average alkalinity required in anaerobic processes is in the range of $2000-4000 \mathrm{mg} \mathrm{CaCO}_{3} / \mathrm{l}$ to maintain the neutral $\mathrm{pH}$. Hence, production and transportation of the required alkalinity agents can be considered as significant up-stream sources of $\mathrm{CO}_{2}$ emission [24].

\section{Conclusions}

The main objective of this study is to provide a framework for making sustainable decisions for selecting suitable wastewater treatment technologies considering the integration of multicriteria (technical, environmental, economic and social). The application of fuzzy-Delphi method indicated that technical criteria, especially treatment efficiency and health and safety risks in the treatment plant are the most important parameters among the studied criteria. The results also revealed that there are other criteria (i.e., technical, economic, environmental and social) that have enough significance to be also considered when deciding on the most suitable industrial effluent treatment technologies.

Overall, the results of this study demonstrate that selection of the treatment methods to deal with industrial effluents cannot strictly be based only on treatment efficiency to satisfy the requirements of sustainable development. Among the treatment methods, membrane-based technologies are identified as the most viable physico-chemical approaches for recalcitrant biowastes mitigation, whereas anaerobic sludge blanket technology can be the most sustainable biological method to deal with highly polluted industrial effluents containing biowastes. The opportunities for improvements of each treatment method have also been discussed while providing a general perspective for the future. In any case, biowastes mitigation is a formidable issue and membrane technologies combined with biological treatment processes appear to be the solution to this problem.

\section{Acknowledgments}


Aveiro Institute of Materials, FCT Ref. UID/CTM/50011/2019, financed by national SFRH/BD/103695/2014 for M. Kamali.

\section{References}

[1] M. Machani, M. Nourelfath, S. D’Amours, S. D’Amours, S. D’Amours, A mathematicallybased framework for evaluating the technical and economic potential of integrating bioenergy production within pulp and paper mills, Biomass and Bioenergy. 63 (2014) 126-139. doi:10.1016/j.biombioe.2014.02.024.

[2] P. Arroyo, M. Molinos-Senante, Selecting appropriate wastewater treatment technologies using a choosing-by-advantages approach, Sci. Total Environ. 625 (2018) 819-827. doi:10.1016/j.scitotenv.2017.12.331.

[3] UNICEF-WHO, Updates Report of the WHO/UNICEF Joint Monitoring Programme for Water Supply and Sanitation. Available at:. http://www.unwater.org/publications/, 2015.

[4] G. Chhipi-Shrestha, K. Hewage, R. Sadiq, Fit-for-purpose wastewater treatment: Testing to implementation of decision support tool (II), Sci. Total Environ. 607-608 (2017) 403-412. doi:10.1016/j.scitotenv.2017.06.268.

[5] M. Kamali, A.A. Alesheikh, S.A. Alavi Borazjani, A. Jahanshahi, Z. Khodaparast, M. Khalaj, Delphi-ahp and weighted index Overlay-GIS approaches for industrial site selection case study: Large extractive industrial units in Iran, J. Settlements Spat. Plan. 8 (2017). doi:10.24193/JSSP.2017.2.03.

[6] M. Kamali, A.A. Alesheikh, Z. Khodaparast, S.M. Hosseinniakani, S.A. Alavi Borazjani, Application of delphi-AHP and fuzzy-GIS approaches for site selection of large extractive industrial units in Iran, J. Settlements Spat. Plan. 6 (2015).

[7] L. Delgado-Antequera, F. Pérez, A.G. Hernández-Díaz, A.D. López-Sánchez, An Interactive Biobjective Method for Solving a Waste Collection Problem, Math. Probl. 
Eng. 2016 (2016). doi:10.1155/2016/5278716.

481

482

483

484

485

486

487

488

489

490

491

492

493

494

495

496

497

498

499

500

501

502

503

504

505

506

507

[8]

C. Aydiner, U. Sen, D.Y. Koseoglu-Imer, E. Can Dogan, Hierarchical prioritization of innovative treatment systems for sustainable dairy wastewater management, J. Clean. Prod. 112 (2016) 4605-4617. doi:10.1016/j.jclepro.2015.08.107.

[9] P.L. Chang, C.W. Hsu, P.C. Chang, Fuzzy Delphi method for evaluating hydrogen production technologies, Int. J. Hydrogen Energy. 36 (2011) 14172-14179. doi:10.1016/j.ijhydene.2011.05.045.

[10] Y.L. Hsu, C.H. Lee, V.B. Kreng, The application of Fuzzy Delphi Method and Fuzzy AHP in lubricant regenerative technology selection, Expert Syst. Appl. 37 (2010) 419-425. doi:10.1016/j.eswa.2009.05.068.

[11] F. Tahriri, M. Mousavi, The application of fuzzy Delphi and fuzzy inference system in supplier ranking and selection, J. Ind. Eng. Int. 10 (2014) 66. doi:10.1007/s40092-0140066-6.

[12] A.P. Sánchez-lezama, J. Cavazos-arroyo, Applying the Fuzzy Delphi method for determining socio-ecological factors that influence adherence to mammography screening in rural areas of Mexico, Cad. Saúde Pública Vol.3o No.2 Rio Janeiro. 30 (2014) 245-258. doi:10.1590/0102-311Xooo25113.

[13] M. Kamali, Z. Khodaparast, Review on recent developments on pulp and paper mill wastewater treatment, Ecotoxicol. Environ. Saf. $114 \quad$ (2015) 326-342. doi:10.1016/j.ecoenv.2014.05.005.

[14] A. Jahanshahi, M. Kamali, M. Khalaj, Z. Khodaparast, Delphi-based prioritization of economic criteria for development of wave and tidal energy technologies, Energy. 167 (2019) 819-827. doi:10.1016/j.energy.2018.11.040.

[15] T. Belton, Valerie, Stewart, Multiple criteria decision analysis, an integrated approach, Springer Berlin Heidelberg, 2002.

[16] M. Kamali, S. D.P., M.E. V. Costa, I. Capela, T.M. Aminabhavi, Sustainability considerations in membrane-based technologies for industrial effluents treatment, Chem. Eng. J. in press (2019). 
[17] M. Dursun, A fuzzy approach for the assessment of wastewater treatment alternatives, Eng. Lett. 24 (2016) 231-236.

[18] X. Ouyang, F. Guo, D. Shan, H. Yu, J. Wang, Development of the integrated fuzzy

[19] A.I. Ban, L. Coroianu, Nearest interval , triangular and trapezoidal approximation of a 
limitations and expectations, Sep. Purif. Technol. 118 (2013) 89-104. doi:10.1016/j.seppur.2013.06.036.

[27] V. Khandegar, A.K. Saroha, Electrocoagulation for the treatment of textile industry effluent-a review., $\quad$ J. $\quad$ Environ. Manage. $128 \quad$ (2013) 949-63. doi:10.1016/j.jenvman.2013.06.043.

[28] P.S. Goh, A.F. Ismail, A review on inorganic membranes for desalination and wastewater treatment, Desalination. 434 (2018) 60-80. doi:10.1016/j.desal.2017.07.023.

[29] M. Kamali, K.M. Persson, M.E. Costa, I. Capela, Sustainability criteria for assessing nanotechnology applicability in industrialwastewater treatment: Current status and future outlook, $\quad$ Environ. Int. $125 \quad$ 261-276. doi:https://doi.org/10.1016/j.envint.2019.01.055.

[30] M. Kamali, M.E. V. Costa, G. Otero-Irurueta, I. Capela, Ultrasonic irradiation as a green production route for coupling crystallinity and high specific surface area in iron nanomaterials, J. Clean. Prod. 211 (2018) 185-197. doi:10.1016/j.jclepro.2018.11.127.

[31] M. Peydayesh, Toraj Mohammadi, O. Bakhtiari, Effective treatment of dye wastewater via positively charged TETA-MWCNT/PES hybrid nanofiltration membranes, Sep. Purif. Technol. 194 (2018) 488-502. doi:10.1016/j.seppur.2017.11.070.

[32] L. Wang, H. Liu, W. Zhang, T. Yu, Q. Jin, B. Fu, H. Liu, Recovery of organic matters in wastewater by self-forming dynamic membrane bioreactor: Performance and membrane fouling, Chemosphere. 203 (2018) 123-131. doi:10.1016/j.chemosphere.2018.03.171.

[33] T. Yan, Y. Ye, H. Ma, Y. Zhang, W. Guo, B. Du, Q. Wei, D. Wei, H.H. Ngo, A critical review on membrane hybrid system for nutrient recovery from wastewater, Chem. Eng. J. 348 (2018) 143-156. doi:10.1016/j.cej.2018.04.166.

[34] S. Daguerre-martini, M.B. Vanotti, M. Rodriguez-pastor, A. Rosal, R. Moral, Nitrogen recovery from wastewater using gas-permeable membranes: Impact of inorganic carbon content and natural organic matter, Water Res. 137 (2018) 201-210. doi:10.1016/j.watres.2018.03.013.

[35] J.R. Scheibler, Everton Ranny Ferreira Santos, A.S. Barbosa, M.G.F. Rodrigues, 
Performance of zeolite membrane (ZSM- $5 / \gamma$-Alumina) in the oil/water separation process, Desalin. Water Treat. 56 (2015) 3561-3567.

566

567

568

569

570

571

572

573

574

575

576

577

578

579

580

581

582

583

584

585

586

587

588

589

590

591

[36] L. Zhu, M. Chen, Y. Dong, C.Y. Tang, A. Huang, A low-cost mullite-titania composite ceramic hollow fi ber micro fi ltration membrane for highly ef fi cient separation of oilin- water emulsion, Water Res. 90 (2016) 277-285. doi:10.1016/j.watres.2015.12.035.

[37] M. Bagheri, S. Ahmad, Critical review of fouling mitigation strategies in membrane bioreactors treating water and wastewater, Bioresour. Technol. 258 (2018) 318-334. doi:10.1016/j.biortech.2018.03.026.

[38] J.N. Hakizimana, B. Gourich, M. Chafi, Y. Stiriba, C. Vial, P. Drogui, J. Naja, Electrocoagulation process in water treatment: A review of electrocoagulation modeling approaches, Desalination. 404 (2017) 1-21. doi:10.1016/j.desal.2016.10.011.

[39] G. Skouteris, D. Hermosilla, P. López, C. Negro, Á. Blanco, Anaerobic membrane bioreactors for wastewater treatment: A review, Chem. Eng. J. 198-199 (2012) 138-148. doi:10.1016/j.cej.2012.05.070.

[40] Y. Hu, X.C. Wang, H.H. Ngo, Q. Sun, Y. Yang, Anaerobic dynamic membrane bioreactor (AnDMBR) for wastewater treatment: A review, Bioresour. Technol. 247 (2018) 11071118. doi:10.1016/j.biortech.2017.09.101.

[41] A.N.L. Ng, A.S. Kim, A mini-review of modeling studies on membrane bioreactor (MBR) treatment for municipal wastewaters, Desalination. 212 (2007) 261-281. doi:10.1016/j.desal.2006.10.013.

[42] A. Babuponnusami, K. Muthukumar, A review on Fenton and improvements to the Fenton process for wastewater treatment, J. Environ. Chem. Eng. 2 (2014) 557-572. doi:10.1016/j.jece.2013.10.011.

[43] N. Wang, T. Zheng, G. Zhang, P. Wang, A review on Fenton-like processes for organic wastewater treatment, J. Environ. Chem. Eng. 4 (2016) 762-787. doi:10.1016/j.jece.2015.12.016.

[44] A.D. Bokare, W. Choi, Review of iron-free Fenton-like systems for activating H2O2in advanced oxidation processes, J. Hazard. Mater. 275 (2014) 121-135. 
[45] M. Anjum, R. Miandad, M. Waqas, F. Gehany, M.A. Barakat, Remediation of wastewater using various nano-materials, Arab. J. Chem. (2016). doi:10.1016/j.arabjc.2016.10.004.

[46] R.C. Olvera, S.L. Silva, E. Robles-Belmont, E.Z. Lau, Review of nanotechnology value chain for water treatment applications in Mexico, Resour. Technol. 3 (2017) 1-11. doi:10.1016/j.reffit.2017.01.008.

[47] M. Khalaj, M. Kamali, Z. Khodaparast, A. Jahanshahi, Copper-based nanomaterials for environmental decontamination - An overview on technical and toxicological aspects, Ecotoxicol. Environ. Saf. 148 (2018) 813-824. doi:10.1016/j.ecoenv.2017.11.060.

[48] K.B. Tan, M. Vakili, B.A. Horri, P.E. Poh, A.Z. Abdullah, B. Salamatinia, Adsorption of dyes by nanomaterials: Recent developments and adsorption mechanisms, Sep. Purif. Technol. 150 (2015) 229-242. doi:10.1016/j.seppur.2015.07.009.

[49] M. Kamali, A.P.D. Gomes, Z. Khodaparast, T. Seifi, Review on recent advances in environmental remediation and related toxicity of engineered nanoparticles, Environ. Eng. Manag. J. 15 (2016) 923-934.

[50] O.Y. Bakather, A.K. Fard, M. Khraisheh, M.S. Nasser, M.A. Atieh, Enhanced Adsorption of Selenium Ions from Aqueous Solution Using Iron Oxide Impregnated Carbon Nanotubes, 2017 (2017). doi:10.1155/2017/4323619.

[51] Y. Tian, H. Li, L. Li, X. Su, Y. Lu, W. Zuo, J. Zhang, In-situ integration of microbial fuel cell with hollow- fi ber membrane bioreactor for wastewater treatment and membrane fouling mitigation, Biosens. Bioelectron. $64 \quad$ (2015) 189-195. doi:10.1016/j.bios.2014.08.070.

[52] M.R. Heydartaemeh, An innovative application of (NiXZnX-X Fe2O4) Mineral nanoparticles for adsorption of Malachite green dye from wastewater effluents, J. Min. Environ. 9 (2018) 143-152. doi:10.22044/jme.2017.5858.1397.

[53] Q. Lin, M. Gao, J. Chang, H. Ma, Adsorption properties of crosslinking carboxymethyl cellulose grafting dimethyldiallylammonium chloride for cationic and anionic dyes, Carbohydr. Polym. 151 (2016) 283-294. doi:10.1016/j.carbpol.2016.05.064. 
[54] K. Bello, B. Kunhanna, B. Narayana, A. Rao, A study on adsorption behavior of newly synthesized banana pseudo-stem derived superabsorbent hydrogels for cationic and anionic dye removal from e ffl uents, Carbohydr. Polym. 181 (2018) 605-615. doi:10.1016/j.carbpol.2017.11.106.

[55] M. Castro, V. Nogueira, I. Lopes, M.N. Vieira, T. Rocha-Santos, R. Pereira, Treatment of a textile effluent by adsorption with cork granules and titanium dioxide nanomaterial, $\mathrm{J}$. Environ. Sci. Heal. - Part A Toxic/Hazardous Subst. Environ. Eng. 53 (2018) 524-536. doi:10.1080/10934529.2018.1425020.

[56] B. Wang, Y. Shui, H. Ren, M. He, Research of combined adsorption-coagulation process in treating petroleum refinery effluent, Environ. Technol. 38 (2017) 456-466. doi:10.1080/09593330.2016.1197319.

[57] M. Hartmann, H. Keller, Wastewater treatment with heterogeneous Fenton-type catalysts based on porous materials, J. Mater. Chem. 20 (2010) 9002-9017. doi:10.1039/cojmoo577k.

[58] O. Koba, L. Biro, Fenton-like reaction: a possible way to efficiently remove illicit drugs and pharmaceuticals from wastewater, Environ. Toxicol. Pharmacol. 9 (2015) 483-488. doi:10.1016/j.etap.2014.12.016.

[59] J. Herney-ramirez, M.A. Vicente, L.M. Madeira, Heterogeneous photo-Fenton oxidation with pillared clay-based catalysts for wastewater treatment: A review, Appl. Catal. B, Environ. 98 (2010) 10-26. doi:10.1016/j.apcatb.2010.05.004.

[6o] O. Sze, N. Sum, J. Feng, X. Hu, P. Lock, Photo-assisted fenton mineralization of an azodye acid black 1 using a modified laponite clay-based $\mathrm{Fe}$ nanocomposite as a heterogeneous catalyst, Top. Catal. 33 (2005) 233-242. doi:10.1007/s11244-005-2532-2.

[61] C. Kuan, S. Chang, S.L.M. Schroeder, Fenton-Like Oxidation of 4-Chlorophenol: Homogeneous or Heterogeneous?, Ind. Eng. Chem. Res. 54 (2015) 8122-8129. doi:10.1021/acs.iecr.5bo2378.

[62] M.L. Rache, A.R. García, H.R. Zea, A.M.T. Silva, L.M. Madeirac, J.H. Ramíreza, Azo-dye orange II degradation by the heterogeneous Fenton- like process using a zeolite Y-Fe 

catalyst - Kinetics with a model based on the Fermi's equation, Appl. Catal. B Environ. 146 (2014) 192-200. doi:10.1016/j.apcatb.2013.04.028.

[63] A. Mirzaei, Z. Chen, F. Haghighat, L. Yerushalmi, Removal of pharmaceuticals from water by homo heterogonous Fenton-type processes - A review, Chemosphere. 174 (2017) 665-688. doi:10.1016/j.chemosphere.2017.02.019.

[64] M. Kamali, I. Capela, M.E. Costa, Ultrasonic Synthesis of Zero Valent Iron Nanoparticles for the Efficient Discoloration of Aqueous Solutions Containing Methylene Blue Dye, in: S. Ul-Islam, B.S. Butola (Eds.), Nanomater. Wet Process. Text., Wiley, 2018: pp. 261284. doi:10.1002/9781119459804.ch8.

[65] M. Kamali, M.E. Costa, I. Capela, Nitrate Removal and Nitrogen Sequestration from Polluted Waters Using Zero-Valent Iron Nanoparticles Synthesized under Ultrasonic Irradiation, in: Adv. Mater. Wastewater Treat., John Wiley \& Sons, Inc., Hoboken, NJ, USA., 2017: pp. 479-505. doi:10.1002/9781119407805.ch13.

[66] S.R. Pouran, A.R.A. Aziz, W. Mohd, A. Wan, Journal of Industrial and Engineering Chemistry Review on the main advances in photo-Fenton oxidation system for recalcitrant wastewaters, J. Ind. Eng. Chem. $21 \quad$ (2015) 53-69. doi:10.1016/j.jiec.2014.05.005.

[67] R. Ramos, D. Scoca, R.B. Merlo, F.C. Marques, F. Alvarez, L.F. Zagonel, Study of nitrogen ion doping of titanium dioxide films, Appl. Soil Ecol. 443 (2018) 619-627. doi:10.1016/j.apsusc.2018.02.259.

[68] J. Hong, C.M. Rico, L. Zhao, A.S. Adeleye, A.A. Keller, J.R. Peralta-Videa, J.L. GardeaTorresdey, Toxic effects of copper-based nanoparticles or compounds to lettuce (Lactuca sativa) and alfalfa (Medicago sativa), Environ. Sci. Process. Impacts. 17 (2015) 177-185. doi:10.1039/C4EMoo551A.

[69] M. Ates, Z. Arslan, V. Demir, J. Daniels, I.O. Farah, Accumulation and Toxicity of CuO and $\mathrm{ZnO}$ Nanoparticles ThroughWaterborne and Dietary Exposure of Goldfish (Carassius auratus), Environ. Toxicol. 24 (2014) 119-128. doi:10.1002/tox.

[70] M. Koltowski, P. Oleszczuk, Effect of activated carbon or biochars on toxicity of different 
soils contaminated by mixture of native polycyclic aromatic hydrocarbons and heavy metals, Environ. Toxicol. Chem. 35 (2016) 1321-1328. doi:10.1002/etc.3246.

[71] F. Deng, S. Wang, H. Xin, Toxicity of CuO Nanoparticles to Structure and Metabolic Activity of Allium cepa Root Tips, Bull. Environ. Contam. Toxicol. 97 (2016) 702-708. doi:10.1007/s00128-016-1934-0.

[72] J.-P. Wang, Y. Chen, Y. Wang, S.-J. Yuan, H. Yu, Optimization of the coagulationflocculation process for pulp mill wastewater treatment using a combination of uniform design and response surface methodology, Water Res. 45 (2011) 5633-5640. doi:10.1016/j.watres.2011.08.023.

[73] I. Kabdaşlı, I. Arslan-Alaton, T. Ölmez-Hancı, O. Tünay, Electrocoagulation applications for industrial wastewaters: a critical review, Environ. Technol. Rev. 1 (2012) 2-45. doi:10.1080/21622515.2012.715390.

[74] Cheng-ChunHe, Ching-YaoHu, Shang-LienLo, Integrating chloride addition and ultrasonic processing with electrocoagulation to remove passivation layers and enhance phosphate removal, Sep. Purif. Technol. $201 \quad$ (2018) 148-155. doi:10.1016/j.seppur.2018.03.011.

[75] Ö.Y. Balik, Serdar Aydin, Coagulation/flocculation optimization and sludge production for pre-treatment of paint industry wastewater, Desalin. Water Treat. 57 (2016) 1269212699. doi:10.1080/19443994.2015.1051125.

[76] Y.Y. Sia, I. Ai, W. Tan, M.O. Abdullah, Adsorption of colour, TSS and COD from palm oil mill effluent (POME) using acid-washed coconut shell activated carbon: Kinetic and mechanism studies, MATEC Web Conf. $87 \quad$ (2017) 03010. doi:10.1051/matecconf/20178703010.

[77] F. Schuchardt, K. Wulfert, T. Herawan, Effect of new palm oil mill processes on the EFB and POME utilization, J. Oil Palm Res. Special Is (2008) 115-126.

[78] Y. Shirai, M. Wakisaka, S. Yacob, A.L.I. Hassan, Reduction of methane released from palm oil mill lagoon in malaysia and its countermeasures, Mitig. Adapt. Strateg. Glob. Chang. 8 (2003) 237-252. 
[79] C. Chiemchaisri, L. Jaitrong, R. Honda, K. Fukushi, K. Yamamoto, Photosynthetic bacteria pond system with infra-red transmitting filter for the treatment and recovery of organic carbon from industrial wastewater, Water Sci. Technol. 56 (2007) 109-116. doi:10.2166/wst.2007.686.

[8o] A. Truppel, J.L. Camargos, R.H. da Costa, P.B. Filho, Reduction of odors from a facultative pond using two different operating practices, Water Sci Technol. 51 (2005) 205-11. doi:10.2166/wst.2005.0463.

[81] S. Liu, Q. Ma, B. Wang, Advanced treatment of refractory organic pollutants in petrochemical industrial wastewater by bioactive enhanced ponds and wetland system, Ecotoxicology. 23 (2014) 689-698. doi:10.1007/s10646-014-1215-9.

[82] M. Belmonte, C. Xavier, J. Decap, M. Martinez, R. Sierra-alvarez, G. Vidal, Improved aerobic biodegradation of abietic acid in ECF bleached kraft mill effluent due to biomass adaptation, J. Hazard. Mater. 135 (2006) 256-263. doi:10.1016/j.jhazmat.2005.11.061.

[83] C.R. Xavier, A. Mosquera-corral, J. Becerra, V. Hernández, G. Vidal, Activated sludge versus aerated lagoon treatment of kraft mill effluents containing $\beta$-sitosterol and stigmasterol, J. Environ. Sci. Heal. Part A. 44 (2009) 327-335. doi:10.1080/10934520802659646.

[84] M.A. Hubbe, J.R. Metts, D. Hermosilla, M.A. Blanco, L. Yerushalmi, F. Haghighat, P. Lindholm-Lehto, Z. Khodaparast, M. Kamali, A. Elliott, Wastewater treatment and reclamation: A review of pulp and paper industry practices and opportunities, BioResources. 11 (2016). doi:10.1016/j.seppur.2011.07.002.

[85] T. Meyer, E.A. Edwards, Anaerobic digestion of pulp and paper mill wastewater and sludge., Water Res. 65 (2014) 321-349. doi:10.1016/j.watres.2014.07.022.

[86] M. Kamali, T.T. Gameiro, M.E.V. Costa, I. Capela, Anaerobic digestion of pulp and paper mill wastes - An overview of the developments and improvement opportunities, Chem. Eng. J. 298 (2016) 162-182. doi:10.1016/j.cej.2016.03.119. 


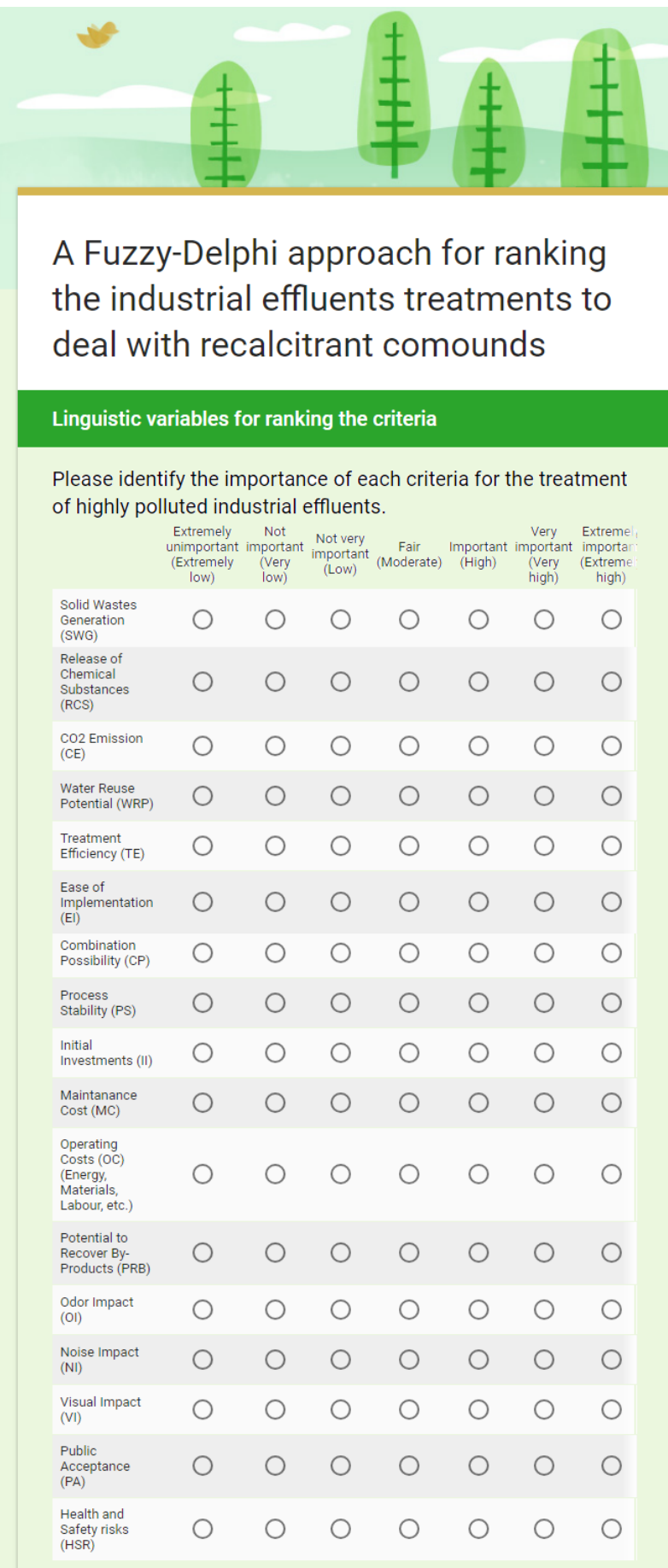




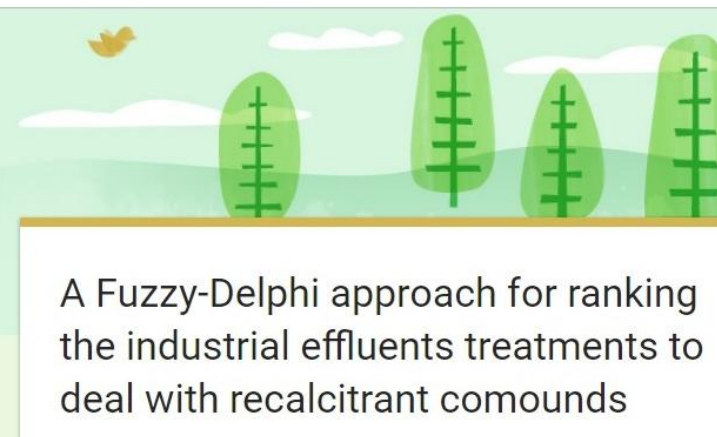

Electrocoagulation

Linguistic variables for rating the method.

Please fill this section if you have previous experience using this method otherwise you can proceed to next section by clicking NEXT button.

Please rate the method in terms of the studied criteria.

veryGood Good Fair Bad very Bad

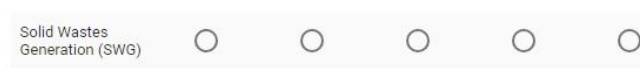

$\begin{array}{lllll}\begin{array}{l}\text { Releaze of } \\ \text { Chemical }\end{array} & 0 & 0 & 0 & 0\end{array}$

$\begin{array}{llllll}\begin{array}{l}\text { Releaze of } \\ \text { Chemical } \\ \text { Substances (RCS) }\end{array} & 0 & 0 & 0 & 0 & 0\end{array}$

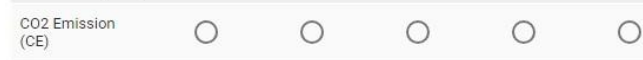

$\begin{array}{llllll}\text { Water Reuse } \\ \text { Potential (WRP) } & 0 & 0 & 0 & 0 & 0\end{array}$

$\begin{array}{lllll}\begin{array}{l}\text { Treatment } \\ \text { Efficiency (TE) }\end{array} & \bigcirc & \bigcirc & \bigcirc & \bigcirc\end{array}$

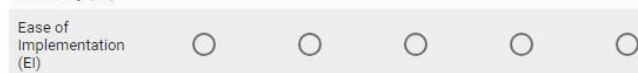

$\begin{array}{llllll}\begin{array}{l}\text { Combination } \\ \text { Possibility (CP) }\end{array} & 0 & 0 & 0 & 0 & 0\end{array}$

$\begin{array}{llllll}\begin{array}{l}\text { Process Stability } \\ \text { (PS) }\end{array} & 0 & 0 & 0 & 0 & 0\end{array}$

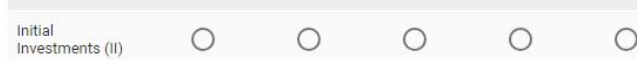

$\begin{array}{llllll}\begin{array}{l}\text { Maintanance } \\ \text { cost }(M C)\end{array} & 0 & 0 & 0 & 0 & 0\end{array}$

Operating costs

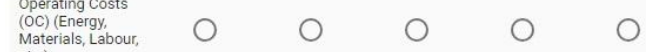

$\begin{array}{lllll}\begin{array}{l}\text { Potential to } \\ \text { Recover By- } \\ \text { Products (PRB) }\end{array} & 0 & 0 & 0 & 0\end{array}$

$\begin{array}{lllll}\text { Odor Impact (OI) } & \mathrm{O} & \mathrm{O} & \mathrm{O} & 0\end{array}$

$\begin{array}{lllll}\text { Noise Impact (NI) } & 0 & 0 & 0 & 0\end{array}$

$\begin{array}{llllll}\operatorname{Visual}_{\text {IImpact }(\mathrm{VI})} \mathrm{O} & \mathrm{O} & 0 & 0 & 0\end{array}$

$\begin{array}{llllll}\begin{array}{l}\text { Public } \\ \text { Acceptance (PA) }\end{array} & 0 & 0 & 0 & 0 & 0\end{array}$

$\begin{array}{llllll}\begin{array}{l}\text { Health and Safety } \\ \text { Considerations } \\ \text { (HSC) }\end{array} & 0 & 0 & 0 & 0 & 0\end{array}$

BACK NEXT 
Supplementary Material
Click here to download Supplementary Material: Supplementary Information.docx

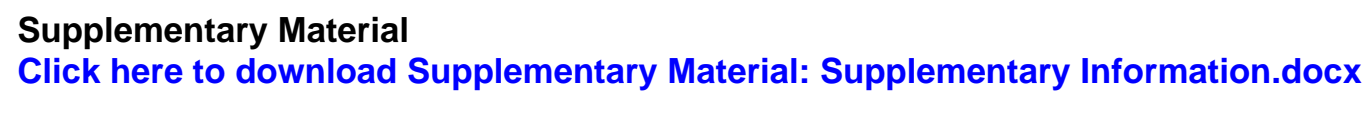

X

年

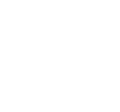

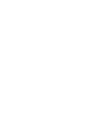

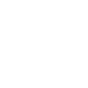

(n)

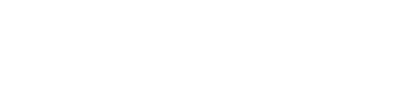

- 